(c) 2018. This manuscript version is made available under the CC-BY-NC-ND 4.0 license http:// creativecommons.org/licenses/by-nc-nd/4.0/ 


\title{
A grey approach to predicting healthcare performance
}

\section{Md. Hafizur Rahman, Tasmia Jannat Tumpa, Syed Mithun Ali*}

Department of Industrial and Production Engineering, Bangladesh University of Engineering and Technology,

Dhaka-1000, Bangladesh.

\section{Sanjoy Kumar Paul}

UTS Business School, University of Technology Sydney, Australia

Email: hafiz.buetipe@gmail.com (M.H. Rahman), tasmia.jannat.tumpa@gmail.com (T.J. Tumpa), syed.mithun@gmail.com (S.M. Ali), sanjoy.paul@uts.edu.au (S.K. Paul)

$$
\text { *Corresponding author: Tel-+8801916034096 }
$$

\begin{abstract}
:
The success of an organization or a particular activity is evaluated through the measurement of key performance indicators (KPIs). The aim of this paper is to analyze and predict the indicators of healthcare performance using grey systems theory. Recent advancements in science and technology have made the healthcare industry extremely efficient at collecting data using electronic claims systems such as electronic health records. Therefore, collecting field level primary data becomes easier and accumulate them to generate secondary data for research purpose and to get an insight of the organization performance is absolutely necessary. Our research analyzes the KPIs of a hospital based on a secondary data source. Since, secondary data contains uncertainty and sometimes poor information, grey prediction model suits best to make a prediction model in this regard. Conventional grey model has considerable drawbacks while making a rigorous prediction model. For this, we apply an improved grey prediction model to predict the KPIs of the healthcare performance indicators. Several error measures in our model give a best fit of the data and allow prediction of the KPIs. The prediction model gives good estimates of the quantitative indicators and produced error rate within an acceptable range. We observe that the KPIs of bed turnover rate (BTR) and bed occupancy rate (BOR) have an increasing trend, whereas the KPIs of average length of stay (ALOS), hospital death rate (HDR) and hospital infection rate (HIR) show a decreasing trend over time. The main contribution of this research is a grey-based prediction model that can provide managers with the information they need to evaluate and predict the performance of a hospital. The research indicates that managers should give greater priority to the indicators which will result in better patients' satisfaction and improved profit margin. Healthcare managers striving towards better
\end{abstract}


performance will now have an empirical basis upon which to formulate and adjust their strategies, after analyzing the predicted value.

Keywords: Healthcare performance, improved grey prediction model, hospital key performance indicators.

\section{Introduction}

Performance evaluation of an enterprise is necessary to balance the inputs and outputs (Leggat et al., 1998; Wu et al; 2012); it is the process of recognizing and quantifying the quality of service provided by an organization (Neely et al., 2002). Performance measurement is the evaluation of an organization's management and the value they give to customers and other stakeholders (Moullin, 2007; Toloo and Tichý, 2015). Measuring performance is a perennial issue for organizations trying to maintain a standard, requiring an evaluation framework that helps managers to understand the extent of any discrepancy between the actual and expected outcomes. According to Bassioni et al., (2004), a performance framework is a theoretical structure developed in research that acts as a basis for a company's performance measurement system. Key performance indicators (KPIs) form one framework of performance measurement.

In healthcare, performance means maintaining the wellbeing of patient and achieving business goals at the same time (Bradea and Mărăcine, 2015). Healthcare staff are always under immense pressure to limit costs from increasing expenditure on treatments and to achieve high efficiency to sustain the quality of treatment (Aletras et al., 2007, Weir et al., 2009). Periodic assessment of healthcare performance is needed to ensure the highest quality of patient care. Supeekit et al., (2016) found that the efficiency of three performance groups - patient safety, clinical care and supporting processes - are independent and related to each other. Overall performance rather than individual performance of these groups should be measured to attain patient satisfaction. Elg et al., (2013) found six types of activities that propel performance directly or indirectly which can be the driving factors of improvements in healthcare organizations. Other factors, such as technical and professional inefficiencies, failure to meet customer demands and increasing costs, are continually threatening healthcare systems. Policymakers need a framework to evaluate and predict the current and future status and activities of the system, respectively. Despite the importance of predicting the performance of healthcare facilities, there is a lack of scientific contribution in this field; this paper fills the research gap. In a highly competitive environment, any organization should have prescience of upcoming events. With increasing costs and decreases in available resources, managers in healthcare 
organizations perform additional administrative task alongside operational tasks to compensate for the expenditure (Sorup and Jacobsen, 2013). A prescience of future performance could aid them to perform their task more efficiently, therefore this paper predicts KPI values which may assist managers in planning and acting in the future.

Walburg et al., (2005) investigated the application of the principles of the learning organization, performance management, and the theory and practice of quality management. Magee et al., (2003) found that people are ambivalent to hospital indicators and hospital rankings, and that they tend to distrust government information. A commercial information provider is recommended to gain people's trust, so it follows that a framework is necessary to predict performance and rankings of hospitals. Jones and Spiegelhalter, (2012) considered an improved probabilistic prediction method for healthcare performance indicators using a bidirectional smoothing model; they made a fully probabilistic comparison and checked the uniformity of predictions through p-values. Imamgholi et al., (2014) and Bahadori et al., (2011) used the Pabon Lasso graphic model for comparing the performance of different hospitals or wards within the same hospital. The Pabon Lasso graph divides hospitals into four categories according to performance indicators. Supeekit et al., (2016) evaluated hospital internal supply performance using the DEMATEL-modified ANP method. Dey et al., (2008) proposed a combined AHP-LOGFRAME framework to manage the performance of a healthcare organization. Cucciare and O'Donohue, (2006) predicted the future costs of healthcare organizations using adjusted associated risk, their research resulting in a better risk adjustment model which can predict high-cost patients with chronic medical conditions. Khalifa and Zabani, (2016) utilized health analytics to improve the performance of emergency room (ER) services. Milstein et al., (2015) found that adoption of an electronic health record (EHR) system improves healthcare performance. Grøndahl et al., (2013) predicted patient satisfaction based on person-related conditions, external conditions and the patient's perception of actual care received. Bhatia and Sood, (2017) presented a comprehensive assessment framework to predict probabilistic vulnerability in the health of patients using an artificial neural network (ANN). Bilodeau et al., (2009) performed a quantitative analysis of hospital performance in a non-competitive environment.

Previous studies have only considered a single key performance indicator divided into subindicators to predict healthcare facility performance (Ding et al., 2010). These studies concentrated on a particular group in a healthcare organization in order to manage performance, not to predict future performances. Previous studies were also conducted from a managerial 
point of view, with financial indicators gaining priority. Indicators from patients' point of view have been neglected in most of the papers and overall assessment of healthcare organizations is absent.

Healthcare facilities are facing enormous challenges and pressure due to increasing numbers of patients (Nolte and McKee, 2003). Adaptation of total quality management (TQM) and operational flexibility improves the performance of healthcare systems (Alolayyan et al., 2011). Research focusing on the overall performance indicators of healthcare facilities may aid decision-makers in costing and fixing treatment levels for patients. Moreover, prediction of performances may assist them in designing the level of TQM. The main contributions of our work are now summarized.

- We identify key performance indicators of healthcare units from a review of relevant literature

- We propose an improved grey prediction model to analyze and evaluate key performance indicators of healthcare units. This model gives decision-makers an understanding of how well they are performing, which will guide them in strategic planning to improve performance

- We apply the proposed framework in the Bangladeshi healthcare industry, using an actual case study

The remainder of the paper is structured as follows: section 2 presents a framework for the key performance indicators; section 3 contains the methodology of our research; section 4 presents the practical application of our model; and section 5 contains the result and discussion. Our study ends with the final conclusions given in section 6 .

\section{Conceptualization of the KPIs}

Key performance indicators (KPIs) are the quantifiable information of an organization that demonstrate the activities and structures of the organization (Badawy et al., 2016). In order to assess the performance of a service organization like healthcare, significant key performance indicators are required (Meier et al., 2013). An evidence-based approach to KPIs is used to measure healthcare performance (van der Geer et al., 2009). Identifying and developing healthcare performance indicators is important for monitoring, assessing and managing health systems to improve efficiency and quality (Arah et al., 2003). Arah et al., (2006) identified two major classes of frameworks in healthcare, one of which is the healthcare performance framework. The framework contains key performance indicators to assess and develop 
performance. Veillard et al., (2005) designed a framework for hospital performance where more than 100 indicators were scrutinized through an extensive survey in 20 European countries. Performance indicators have great advantages but encounter some problems when applied to healthcare systems because there are so many performance indicators. It is important to limit the number of performance indicators and select some key performance indicators to assess healthcare performance ( $\mathrm{Gu}$ and Itoh, 2016). A single performance indicator cannot represent the whole of an organization, but analyzing a large number of performance indicators is time consuming and imposes administrative burdens on managers which can result in negative effects on healthcare management services (Furham, 2004). Five key performance indicators - bed turnover rate, bed occupancy rate, average length of stay, hospital death rate, and hospital infection rate - have been identified. These indicators are operationally quantifiable and are calculated after determining several other measures.

\subsection{Bed Turnover (BTO) Rate:}

According to Osborn (2008), BTO is a measurement of how a hospital's resources are utilized, found by counting the changing occupancy of each bed in a hospital. The BTO rate is calculated as:

Bed turnover rate

$$
=\frac{\text { Sum of patients admissions for a given period }}{\text { Average bed counts for the same time period }}
$$

In the case of hospital " $A$ ", they recorded 2560 admissions in their system during the month of January, 2017. Average bed count for the same period was 870; therefore, bed turnover rate was $2560 / 870 \approx 3$, meaning that each bed in the hospital saw three patients treated during the month of January, 2017.

BTO is useful for determining the number of vacant beds available to incoming patients if the hospital is required to admit more, which helps hospital management to plan accommodation accordingly and in advance.

\subsection{Bed Occupancy Rate (BOR):}

Bed occupancy rate is the financial indicator of a hospital, also called the percentage of occupancy. A private hospital generates more revenue when the occupancy rate is high. According to Osborn (2008), the inpatient occupancy rate is the percentage of official beds occupied by the hospital's patient for a given time period. BOR is a measure of the utilization 
of available bed capacity. It compares the number of patients treated by the number of available beds during the period of interest. The formula for bed occupancy rate is:

Bed occupancy rate

$$
=\frac{\text { Sum of inpatient days for a given period } \times 100}{\text { Number of useable beds } \times \text { Number of days in that same period }}
$$

The denominator of equation (2) gives the total number of inpatient bed days counted for that period. In the case of hospital " $A$ ", the total number of inpatient service days in the month of May were 7582 and the inpatient bed days counted were 8920, giving an inpatient bed occupancy rate of $7582 / 8920=85 \%$. The bed occupancy rate can be more than $100 \%$ during an epidemic or disaster when the hospital sets up temporary beds not considered in the official record of the bed count. A low BOR indicates that beds remain vacant for a long time period.

\subsection{Average Length of Stay (ALOS):}

The length of stay is the number of calendar days from a patient's admission to discharge from the system. A longer length of stay indicates longer recovery periods, which may lead to poorer long-term health outcomes (Sullivan et al., 2017). ALOS is sometimes used to indicate efficiency. If all other variables remain constant, a shorter stay may reduce the cost per discharge and shift care from inpatient care to the less expensive post-acute care settings. The indicator is presented for all acute care cases and for childbirth without complications (OECD, 2015). The formula for calculating ALOS is:

Average length of stay

$$
\frac{\text { Total time of a patient staying in the system for a given period }}{\text { Sum of patient releases (including death) for the given period }}
$$

ALOS varies due to conditions specific to the patient's disease. LOS is considered as one day when a patient is admitted and released on the same day, whereas adjustment to the calculation is carried out when a patient is admitted in one month and released in another month.

\subsection{Hospital Death Rate (HDR):}

Death rates are an important factor for management to evaluate the quality of healthcare and performance. Hospital death rate is calculated by considering the total number of patients released from the system, both dead and alive. Several death rates can determine the overall death rate of a healthcare organization, namely the gross death rate, net death rate, new-born death rate, fetal death rate, and maternal death rate. The gross death rate is the proportion of 
total hospital discharges that resulted in deaths. It is the basic mortality indicator of a healthcare facility. New-born death rates are included in the hospital's gross death rate, although it may be calculated separately for each respective department. Stillborn deaths are called fetal deaths as they are neither admitted nor released from the facility. Fetal death rate calculation does not affect the gross death rate as, like the new-born death rate, it is calculated separately. Maternal death is an indicator of prenatal care in a community; healthcare management calculates it separately to identify the factors that could lead to a maternal death. Gross death rate is the overall death rate indicator of the healthcare facility. The formula to calculate gross death rate is:

Hospital death rate

$$
=\frac{\text { Sum of inpatient deaths for a certain period } \times 100}{\text { Sum of released patients from the system in the same period }}
$$

In the case of hospital "A", they had 31 deaths in May, 2017, including adults, children, and new-borns. There were 832 total discharges, including deaths; therefore, the gross death rate was $3.73 \%$.

\subsection{Hospital Infection Rate (HIR):}

Patients in a healthcare facility contract infections when the management fail to properly follow guidelines for safe care. Infections affect a patient's treatment progress and make treatment procedures more complex. Controlling hospital infection is a critical KPI for quality and service improvement (Love et al., 2008). Continuous observation of each unit in the facility is necessary to control the hospital infection rate. Examples of different types of infections are respiratory, gastrointestinal, surgical wound, skin, and urinary tract infections, as well as septicaemias and infections related to intravascular catheters. The formula for calculating nosocomial infection rate is:

Hospital infection rate

$$
=\frac{\text { Total number of hospital infections for a given period } \times 100}{\text { Total number of discharges (including deaths) for the same period }}(5)
$$

For example, hospital "X" discharged 725 patients during the month of April, 2017. 32 of these patients had hospital-acquired infections; therefore, the hospital-acquired infection rate was $4.4 \%$.

A brief summary of our key performance indicators (KPIs) selected from the literature is presented in Table 1. 


\begin{tabular}{|c|c|c|}
\hline Indicators & Definition & Authors \\
\hline $\begin{array}{l}\text { Bed Turnover } \\
\text { Rate (BTR) }\end{array}$ & $\begin{array}{l}\text { The number of times each hospitals bed } \\
\text { changes occupants. It is a measure of } \\
\text { hospital utilization }\end{array}$ & $\begin{array}{l}\text { Bahadori et al., (2011) } \\
\text { Goshtasebi et al., (2009) } \\
\text { Cunningham et al., (2005) }\end{array}$ \\
\hline $\begin{array}{l}\text { Average } \\
\text { Length of Stay } \\
\text { (ALOS) }\end{array}$ & $\begin{array}{l}\text { A number of calendar days of a patient's } \\
\text { admission to discharge. It is calculated } \\
\text { after they are discharged from the hospital }\end{array}$ & $\begin{array}{l}\text { Bahadori et al., (2011) } \\
\text { Goshtasebi et al., (2009) } \\
\text { Sullivan et al., (2017) } \\
\text { Protty et al., (2017) }\end{array}$ \\
\hline $\begin{array}{l}\text { Bed } \\
\text { Occupancy }\end{array}$ & $\begin{array}{l}\text { Percentage of functional beds in a hospital } \\
\text { occupied by the inpatients for a given }\end{array}$ & $\begin{array}{l}\text { Belciug and Gorunescu, } \\
\text { (2015) }\end{array}$ \\
\hline Rate (BOR) & $\begin{array}{l}\text { time period. It is a measure of financial } \\
\text { performance }\end{array}$ & Sun et al., (2015) \\
\hline $\begin{array}{l}\text { Hospital Death } \\
\text { Rate (HDR) }\end{array}$ & $\begin{array}{l}\text { Percentage of patients discharged from } \\
\text { the hospital alive or dead. It is the } \\
\text { indicator of mortality in a healthcare } \\
\text { facility }\end{array}$ & Bilow et al., (2016) \\
\hline $\begin{array}{l}\text { Hospital } \\
\text { Infection Rate } \\
\text { (HIR) }\end{array}$ & $\begin{array}{l}\text { Percentage of infection that occurs in } \\
\text { various departments in a hospital. It is a } \\
\text { common measure to determine morbidity } \\
\text { rates }\end{array}$ & $\begin{array}{l}\text { Elsamadicy et al., (2016) } \\
\text { Love et al., (2008) }\end{array}$ \\
\hline
\end{tabular}

\section{Methodology}

Grey systems theory was developed by Deng, (1989); it is a relatively new methodology focusing on problems involving small data and poor information. It addresses uncertain systems with partially known and partially unknown information through generating, excavating and extracting useful information from what is available (grey systems research). Inexactness, unreliability, and the border with ignorance are the sorts of inadequate information which lead to uncertainty of a system or data (Funtowicz and Ravetz, 1990), although uncertainty can also exist in a system where a lot of information is available (van Asselt and Rotmans, 2002). Grey systems theory has received attention from many researchers in different fields dealing with inaccurate and obscure datasets (Kang and Zhao, 2012; Tsai and Lu, 2015; Liu et al., 2012; Liao et al., 2013, Unnikrishna Pillai et al., 2018). The theory enables a correct description of a system's running behaviour and its evolution law, and thus generates 
quantitative predictions of future system changes. Both the input random variables and the output function values contain aleatory or epistemic uncertainty. Uncertainty in the system comes from incomplete and inaccurate information. A lack of information about the system, or imprecise probabilistic information, evolves into epistemic uncertainty (Zaman and Mahadevan, 2013). Liu et al., (2012) point out that pursuing a meticulous model in the presence of uncertainty is impossible. In this study, uncertainty exists if the source information of the data is unknown because the whole model is applied to a secondary data set. Source dependency or data value determination does not affect the grey forecasting model; therefore, prediction of periodic assessment of any datasets can be done using the grey model (Rajesh, 2016; Lee et al., 2014; Tsai and Lu, 2015; Xia et al., 2015). Periodic datasets show a common trend, such as increasing or decreasing. The grey prediction model can capture the trend and predict the values of periodic measures in the upcoming period. Several error measures are used to fit the dataset and produce less error, which results in a good prediction (Liu and Lin, 2011; Samvedi and Jain, 2013). A number of research have been reported in the literature to improve the accuracy of grey prediction. Some proposed methodologies to calculate the background value of GM $(1,1)$ model can be found in Madhi and Mohamed (2017), Xiaofei and Renfang (2014), Li (2011), Hua (2009), and Tan (2000). Table 2 shows some research where the researchers applied improved grey prediction model to check the model effectiveness in different fields.

Table 2: Some research using the improved grey prediction model
\begin{tabular}{lll} 
SL. No. & Reference & Focused Area \\
\hline 1 & Mao and Chirwa, (2006) & Vehicle fatality risk estimation \\
2 & Li et al., (2012) & Aquaculture water quality prediction \\
3 & Rajesh, (2016) & Supply chain performance resilience prediction \\
4 & Hsu and Wen, (1998) & Air passenger market prediction \\
5 & Y. Wang et al., (2010) & Reliability growth prediction \\
6 & Q. Wang et al., (2017) & Prediction of tertiary industry \\
7 & Kang and Zhao, (2012) & Load forecasting of power engineering
\end{tabular}

In a real scenario, there may be some noise in the data that does not represent the true behavior of the system. The grey prediction model tackles such noises, and a series of error checks ensure best fit of the data. The procedure for forecasting using the improved grey model is presented below.

\section{Step 1: Determination of the Periodic Key Performance Indicators}

The value of selected key performance indicators can be calculated after obtaining healthcare system data using the formulae previously mentioned in this article. KPIs for a certain $t^{\text {th }}$ period can be calculated from the dataset where $1 \leq t \leq m$. Let, 
$X^{(0)}=\left(\chi^{(0)}(t)\right)_{t=1}^{m}(6)$

$\chi^{(0)}(t)$ is the raw data from the secondary source which represents a zero order monthly indicator for the $t^{\text {th }}$ time period. The time sequence of zero order data is:

$X=(\chi(1), \chi(2), \chi(3), \ldots \ldots \ldots(m))(7)$

The time sequence for each period is considered as the indicator of that period. Here, $\chi(1)$ is the KPI for the first period of our concerned time period.

\section{Step 2: Application of Buffer Operators}

True changes in the system over time cannot be represented if the periodic data sequence evolves too quickly or slowly due to external factors. Data sequences with external disturbances cannot be used to build the model. In such cases, to improve the accuracy of the prediction model we must apply sequential strengthening operators or weakening sequence operators. If $F$ be an ordering sequence on $X$ then,

$X F=(\chi(1) f, \chi(2) f, \chi(3) f, \ldots \ldots \ldots, \chi(m) f)(8)$

Weakening and strengthening operators can be applied respectively for the following conditions,

$\chi(u) f \geq \chi(u) ; u=1,2,3, \ldots \ldots . ., m(9)$

$\chi(u) f \leq \chi(u) ; u=1,2,3, \ldots \ldots \ldots, m(10)$

If $\chi(3) f \leq \chi(3)$ for the third period, then the ordering sequence $F$ is a strengthening operator and the function is an increasing function. The opposite of this will be a decreasing function. The values expand when we apply strengthening operators and compress when a weakening operator is applied. To smooth the values, a second order weakening operator, $F^{2}$, is applied.

$X^{(0)} F=\left(\chi^{(0)}(1) f, \chi^{(0)}(2) f, \chi^{(0)}(3) f, \ldots \ldots \ldots \chi^{(0)}(m) f\right)(11)$

Where,

$\chi^{(0)}(u) f=\frac{1}{m-k+1}\left(\chi^{(0)}(u)+\chi^{(0)}(u+2)+\chi^{(0)}(u+3)+\ldots+\chi^{(0)}(m)\right)(12$

And

$$
X^{(0)} F^{2}=\left(\chi^{(0)}(1) f^{2}, \chi^{(0)}(2) f^{2}, \chi^{(0)}(3) f^{2}, \ldots \ldots \ldots, \chi^{(0)}(m) f^{2}\right)(13
$$

Where, 


$$
\chi^{(0)}(u) f^{2}=\frac{1}{m-u+1}\left(\chi^{(0)}(u) f+\chi^{(0)}(u+2) f+\chi^{(0)}(u+3) f+\ldots+\chi^{(0)}(m) f\right)
$$

$\tilde{X}$ is introduced to represent the sequential values after applying the second order weakening operator from equation (14),

$$
X^{(0)} F^{2}=\tilde{X}=\left(\tilde{\chi}^{(0)}(1), \tilde{\chi}^{(0)}(2), \tilde{\chi}^{(0)}(3), \ldots \ldots \ldots, \tilde{\chi}^{(0)}(m)\right)(15)
$$

\section{Step 3: Calculation of Accumulating Operators}

The first accumulation generated sequence (1-AGO) is the sequential aggregation of the KPIs within the concerned time period, calculated after determining the second order weakening operators. The aggregated values are represented by $\tilde{X}^{(1)}$ as follows:

$\tilde{X}^{(1)}=\left(\tilde{\chi}^{(1)}(1), \tilde{\chi}^{(1)}(2), \tilde{\chi}^{(1)}(3), \ldots \ldots \ldots, \tilde{\chi}^{(1)}(m)\right)(16)$

Where,

$\tilde{\chi}^{(1)}(u)=\sum_{t=1}^{u} \tilde{\chi}^{(0)}(t) ; u=1,2,3, \ldots \ldots \ldots, m(17)$

\section{Step 4: Calculation of the Adjacent Neighbour Means of the Sequence}

The adjacent neighbour means of the data sequence are calculated after applying the first accumulated generated sequence in the data. Consecutive neighbouring means of the data for each KPI within the concerned time period are presented by $\dot{X}$ as follows:

$\dot{X}=\left(\dot{\chi}^{(1)}(1), \dot{\chi}^{(1)}(2), \dot{\chi}^{(1)}(3), \ldots \ldots \ldots, \dot{\chi}^{(1)}(m)\right)(18)$

Where,

$\dot{\chi}^{(1)}(1)=\frac{1}{2}\left(\tilde{\chi}^{(1)}(u)+\tilde{\chi}^{(1)}(u+1)\right) ; u=1,2,3, \ldots \ldots \ldots, m(19)$

An improved method, suggested by Tan (2000) to calculate the mean generating operator when data sequences show quick growth, is based on the background value of the grey model GM $(1,1)$ in Eq. $(27)$. GM $(1,1)$ performs well with equidistance and slow growth of time sequence data, but often performs very poorly, making delay errors, with quick growth time sequence data. The improved method has increased the acceptability of the GM $(1,1)$ to many researchers.

The improved equation of calculating the mean generating operator is given as, 
$\dot{\chi}^{(1)}(u+1)=\frac{1}{n}\left[\varphi(n+1) \chi^{1}(u)+\omega(n-1) \chi^{1}(u+1)\right](20)$

Where, $\varphi, \omega$ are the parameters having typical values of both 0.5 and,

$\mathrm{n}=\left(\sum_{t=2}^{m} \frac{\chi^{1}(t)}{\chi^{1}(t-1)}\right)^{\frac{1}{m-1}}$

\section{Step 5: Generate the Sequential Values of the KPIs}

The basic form of $\operatorname{GM}(1,1)$ is represented as,

$\tilde{\chi}^{(0)}(u)+\alpha \dot{\chi}^{(1)}(u+1)=\beta(22)$

Equation (22) is also called the even form of GM $(1,1)$, which is a first order differential equation of the following form,

$\frac{d \tilde{\chi}^{(1)}}{d t}+\alpha \tilde{\chi}^{(1)}=\beta$

The estimated values of the parameters $\alpha, \beta$ are then calculated using the least square method as follows,

$\left.\widehat{\alpha \hat{\alpha}}=[\alpha, \beta]^{T} 24\right)$

Where $\hat{\alpha}$ is the sequential representation of the parameters, determined as follows,

$\hat{\alpha}=\left(\left[B^{T} B\right]^{-1} B^{T} Y\right)(25)$

Matrices $Y$ and $B$ are constructed as follows,

$Y=\left[\begin{array}{c}\tilde{\chi}^{(0)}(2) \\ \tilde{\chi}^{(0)}(3) \\ \tilde{\chi}^{(0)}(4) \\ \vdots \\ \tilde{\chi}^{(0)}(m)\end{array}\right] ; B=\left[\begin{array}{cc}-\dot{\chi}^{(1)}(2) & 1 \\ -\dot{\chi}^{(1)}(3) & 1 \\ -\dot{\chi}^{(1)}(4) & 1 \\ \vdots & \vdots \\ -\dot{\chi}^{(1)}(m) & 1\end{array}\right]$

where $B$ is the data matrix.

$\hat{\alpha}$ can also be calculated after replacing appropriate values in equation (25), which results in the following expression, 
$\hat{\alpha}=\left[\begin{array}{c}\frac{\left(\left(\frac{1}{m-1}\left(\Sigma_{u=2}^{m} \tilde{\chi}^{(0)}(u) \times \sum_{u=2}^{m} \dot{\chi}^{(1)}(u)\right)\right)-\left(\sum_{u=2}^{m}\left(\tilde{\chi}^{(0)}(u) \times \dot{\chi}^{(1)}(u)\right)\right)\right.}{\left(\sum_{u=2}^{m}\left[\dot{\chi}^{(1)}(u)\right]^{2}-\frac{1}{m-1}\left[\Sigma_{u=2}^{m} \dot{\chi}^{(1)}(u)\right]^{2}\right)} \\ \left(\frac{1}{m-1}\left(\sum_{u=2}^{m} \tilde{\chi}^{(0)}(u)+\alpha \sum_{u=2}^{m} \dot{\chi}^{(1)}(u)\right)\right)\end{array}\right]$

The time response sequence of the data can be calculated after determining the solution of the whitenization equation (23) and estimating the values of parameters $\alpha, \beta$.

$\hat{\chi}^{(1)}(u+1)=\left(\left[\tilde{\chi}^{(0)}(1)-\left(\frac{\beta}{\alpha}\right)\right] e^{-\alpha u}+\left(\frac{\beta}{\alpha}\right)\right) ; u=0,1,2,3, \ldots \ldots, m-1(28)$

$\hat{\chi}^{(0)}(u+1)=\hat{\chi}^{(1)}(u+1)-\hat{\chi}^{(1)}(u)(29)$

From the above two equations, the simulated sequence can be obtained from,

$\hat{X}=\left(\left(\hat{\chi}^{(0)}(u)\right)_{u=1}^{m}\right)(30)$

\section{Step 6: Error Checking}

After simulating the data sequence, we obtain data closer to the original data, which is the case here after applying a second order weakening operator, $\tilde{x}^{(0)}(k)$. The closer these two values are, the more accurate a prediction model we will get. Therefore, error checking is carried out to increase the accuracy of the model. Sequential error of the data is calculated as,

$\varepsilon^{(0)}=\left(\varepsilon^{(0)}(u)\right)_{u=1}^{m}(31)$

Where,

$\varepsilon^{(0)}(u)=\left(\tilde{\chi}^{(0)}(u)-\hat{\chi}^{(0)}(u)\right)(32)$

Next, relative error is calculated. $\Delta$ represents the sequence of relative errors,

$\Delta=\left(\delta_{u}\right)_{u=1}^{m}$

Where,

$\delta_{u}=\frac{\left|\varepsilon^{(0)}(u)\right|}{\tilde{x}^{(0)}(u)}(34)$

Average relative error is then determined as follows, 
$\bar{\Delta}=\frac{1}{m}\left(\sum_{i=1}^{n} \delta_{i}\right)$

And the filtering error,

$\emptyset=\delta_{m}(36)$

We set a permissible limit on the relative error as 0.02 . The exactness of simulated data can then be calculated, which should be greater than 0.9 . When these two conditions are satisfied, the absolute degree of grey incidences $(\epsilon)$ of $\tilde{X}$ and $\hat{X}$ can be computed as,

$$
\begin{aligned}
& |s|=\left|\left(\sum_{u=2}^{m-1}[\tilde{\chi}(u)-\tilde{\chi}(1)]\right)+\left(\frac{1}{2}[\tilde{\chi}(m)-\tilde{\chi}(1)]\right)\right|(37) \\
& |\hat{s}|=\left|\left(\sum_{u=2}^{m-1}[\hat{\chi}(u)-\hat{\chi}(1)]\right)+\left(\frac{1}{2}[\hat{\chi}(m)-\hat{\chi}(1)]\right)\right|(38)
\end{aligned}
$$

$|\hat{s}-s|=$

$\left|\left(\sum_{u=2}^{m-1}([\hat{\chi}(u)-\hat{\chi}(1)]-[\tilde{\chi}(u)-\tilde{x}(1)])\right)+\left(\frac{1}{2}([\hat{\chi}(m)-\hat{\chi}(1)]-[\tilde{\chi}(m)-\tilde{\chi}(1)])\right)\right|$

Thus,

$\epsilon=\frac{1+|s|+|\hat{s}|}{1+|s|+|\hat{s}|+|\hat{s}-s|}(40)$

If $\epsilon>0.90$, then the degree of incidence is in level 1 .

The ratio of mean square deviations, or the variance ratio $(C)$, is computed as follows,

$\bar{\chi}=\frac{1}{m} \sum_{u=1}^{m} \tilde{\chi}^{(0)}(u)$

$S_{1}^{2}=\frac{1}{m} \sum_{u=1}^{m}\left[\tilde{\chi}^{(0)}(u)-\bar{\chi}\right]$

$\bar{\varepsilon}=\frac{1}{m} \sum_{u=1}^{m} \varepsilon^{(0)}(u)(43)$

$S_{2}^{2}=\frac{1}{m} \sum_{u=1}^{m}\left[\varepsilon^{(0)}(u)-\bar{\varepsilon}\right]^{2}(44)$

$C=\frac{S_{2}}{S_{1}}(45)$

If $C<0.35$, then it is in level 1 . 
The small error probability can be determined from the following equation,

$\exists=0.6745 \times S_{1}(46)$

Then, we check that,

$p=\left(P\left|\varepsilon^{(0)}(k)-\bar{\varepsilon}\right|<\exists\right),(47)$

If the condition $(p>0.95)$ is true, the accuracy is checked and we can apply the grey model for prediction.

The standard of judgement is presented in Table 3.

Table 3: Standard to judge the error measurement
\begin{tabular}{lllll} 
Precision grade & Excellent & Pass & Likely to pass & No pass \\
\hline Little error probability (p) & $>0.95$ & $>0.80$ & $>0.75$ & $\leq 0.70$ \\
Variance ratio (C) & $<0.35$ & $<0.60$ & $<0.65$ & $\geq 0.65$
\end{tabular}

\section{Step 7: Making the Prediction}

Now we can predict the values of KPIs as the errors checks have been satisfied. The predicted values of the next $i$ periods can be calculated from equations 12 and 13 .

$\hat{X}=\left(\hat{\chi}^{(0)}(t)\right)_{t=m}^{m+i}(48)$

A flow diagram is presented in Figure 1 so the reader can understand the steps involved. 


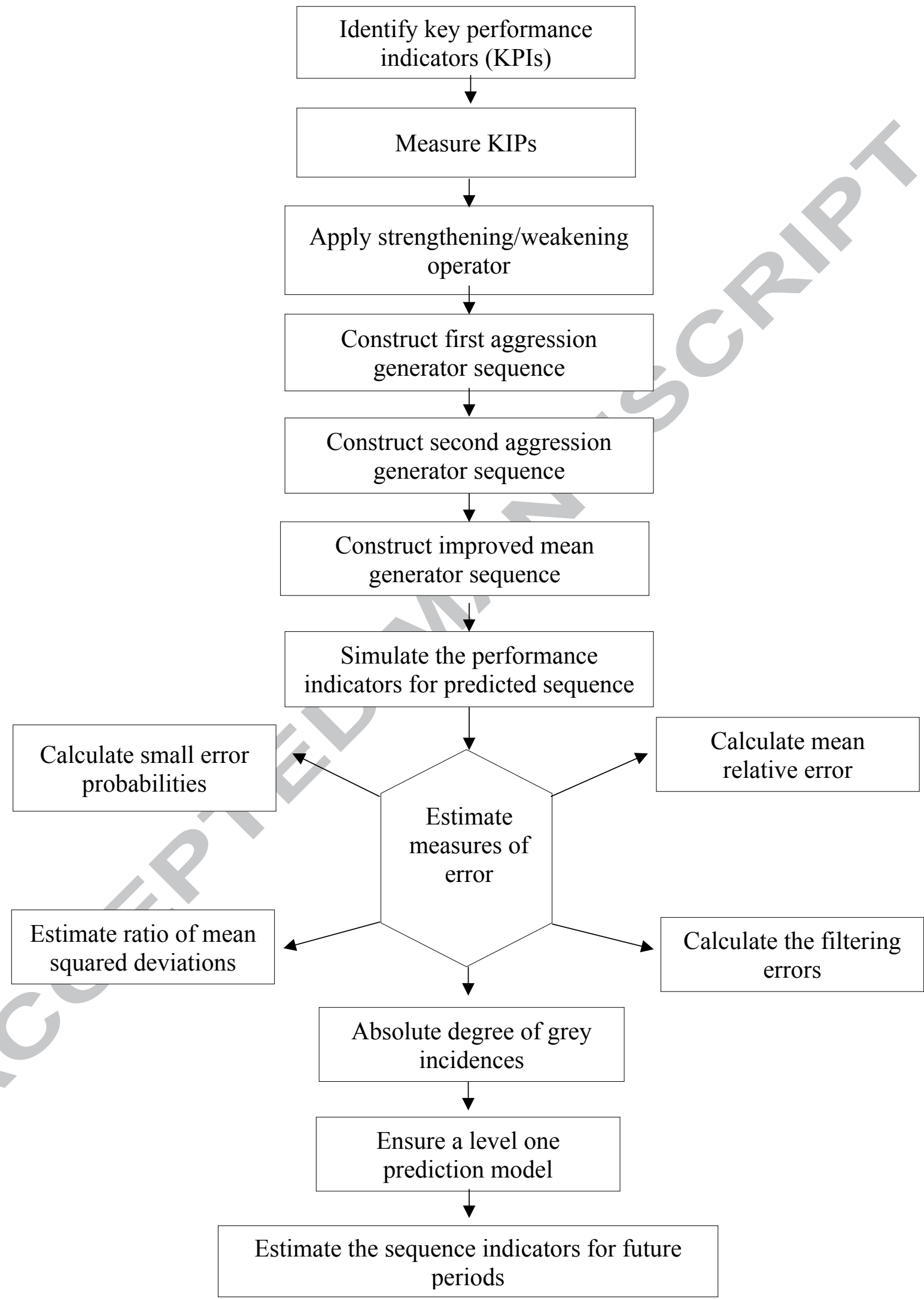

Figure SEQ Figure ${ }^{*}$ ARABIC 1: Flowchart of improved grey prediction model (ADDIN

CSL_CITATION \{ "citationItems" : [ \{ "id" : "ITEM-1", "itemData" : \{ "DOI" :

"10.1016/j.elerap.2016.09.006", "ISSN" : "15674223", "author" : [ \{ "dropping-particle" : 


\section{Grey model, GM $(1,1)$, application in healthcare performance prediction}

\subsection{Descriptive background}

Healthcare involves a diverse set of public and private data collection systems. These data collection systems includes health surveys, administrative enrolment and billing records, and medical records which are used by various entities, including hospitals. The prediction model is applied here to a public hospital in Bangladesh.

Bangladesh, the eighth most populous country in the world, has the lowest expenditure (US\$ 27 per capita annually) and is now facing unprecedented demands on public and private hospitals. Despite poverty, Bangladesh has achieved tremendous improvements in healthcare (Ahsan and Bartlema, 2004); however, increasing costs of diagnostic and treatment procedures are creating confusion in an ageing population over whether the cost is worth it or not. Over the last few years, health providers in both private and public sectors focused on increasing the amount of physical infrastructure (hospitals, clinics, diagnostic centers, etc.) which gave a greater benefit to the people as they had more access to healthcare systems.

Hospitals and healthcare systems are full of information; however, in Bangladesh, information collection is not satisfactory and the gathered data contains a lot of missing data and distorted information. GM $(1,1)$ is the best model to predict performance in such an uncertain environment. We applied this model to a secondary dataset as hospitals generally do not share primary information, because these data are confidential. The authority did not reveal the main source of data but they confirmed their formula to measure indicators were the same as described in Section 2 of this article. The collected data shows monotonically increasing and decreasing orders for the indicators, due to adaption of total quality management (TQM).

\subsection{Data collection and aggregation}

We collected data from a hospital in Bangladesh for the period of five months from January, 2017 to May, 2017. They are specialized in detecting birth defects and thus help women to deliver healthy babies. In case of complex situation, they monitor the genetic conditions through ultrasound and provide special care for the mother and to-be-born babies in their facility. The hospital is equipped with state-of-the-art technologies and the management is set to adopt continuous improvement strategies that will help them to reduce the values of the KPIs having a negative impact on hospital performance and increase the values of those KPIs which will generate more profit and reputation. Therefore, a prediction model based on accumulated 
data will help them to deduce their future actions. Secondary data to analyze using improved grey model for each KPIs calculated using Eq. (1) to Eq. (5) are presented in Tables 4, 5, 6, 7 and 8.

Table 4: KPI 1-Bed Turnover Rate (BTR) value from January, 2017-May, 2017

\begin{tabular}{|c|c|c|c|c|}
\hline \multirow{2}{*}{$\begin{array}{l}\text { Time period } \\
\text { Month }\end{array}$} & \multicolumn{3}{|c|}{ Bed Turnover Rate (BTR) } & \multirow{7}{*}{$\begin{array}{c}\text { Table 5: KPI 2-Bed } \\
\text { Occupancy Rate (BOR) } \\
\text { value from January, } \\
2017-\text { May, } 2017\end{array}$} \\
\hline & Total patients & Avg. bed counts & BTR & \\
\hline Jan-17 & 670 & 103 & 6.5 & \\
\hline Feb-17 & 956 & 121 & 7.9 & \\
\hline Mar-17 & 1144 & 133 & 8.6 & \\
\hline Apr-17 & 966 & 105 & 9.2 & \\
\hline May-17 & 882 & 90 & 9.8 & \\
\hline Time period & \multicolumn{3}{|c|}{ Bed Occupancy Rate (BOR) } & \multirow{3}{*}{$\begin{array}{c}\text { Table 6: KPI 3-Average } \\
\text { Length of Stay (ALOS) } \\
\text { value from January, } \\
\text { 2017-May, } 2017\end{array}$} \\
\hline Month & Inpatient Days & Inpatient bed days & $B O R$ & \\
\hline Jan-17 & 2586 & 3193 & 0.810 & \\
\hline Feb-17 & 2948 & 3388 & 0.870 & \multirow{4}{*}{$\begin{array}{c}\text { Table 7: KPI 4- Hospital } \\
\text { Death Rate (HDR) value } \\
\text { from January, 2017-May, } \\
2017\end{array}$} \\
\hline Mar-17 & 3711 & 4123 & 0.900 & \\
\hline Apr-17 & 2914 & 3150 & 0.925 & \\
\hline May-17 & 2631 & 2790 & 0.943 & \\
\hline Time period & \multicolumn{3}{|c|}{ Average Length of Stay (ALOS) } & \multirow{8}{*}{$\begin{array}{c}\text { Table 8: KPI 4- Hospital } \\
\text { Death Rate (HDR) value } \\
\text { from January, 2017- May, } \\
2017\end{array}$} \\
\hline Month & Inpatient Days & Discharges & $A L O S$ & \\
\hline Jan-17 & 2586 & 202 & 12.8 & \\
\hline Feb-17 & 2948 & 254 & 11.6 & \\
\hline Mar-17 & 3711 & 379 & 9.8 & \\
\hline Apr-17 & 2914 & 317 & 9.2 & \\
\hline May-17 & 2631 & 310 & 8.5 & \\
\hline Time period & \multicolumn{3}{|c|}{ Hospital Death Rate } & \\
\hline Month & Total deaths & Discharges & $H D R$ & \multirow{6}{*}{$\begin{array}{l}\text { The methodology } \\
\text { described in section } 3 \text { was } \\
\text { implemented to predict the } \\
\text { performance of the }\end{array}$} \\
\hline Jan-17 & 7 & 202 & 3.3 & \\
\hline Feb-17 & 7 & 254 & 2.8 & \\
\hline Mar-17 & 10 & 379 & 2.6 & \\
\hline Apr-17 & 7 & 317 & 2.1 & \\
\hline May-17 & 6 & 310 & 1.8 & \\
\hline Time period & \multicolumn{3}{|c|}{ Hospital Infection Rate (HIR) } & hospital in future periods. \\
\hline Month & Total infections & Discharges & $B T R$ & \multirow{6}{*}{$\begin{array}{l}\text { GM }(1,1) \text { employs a lot } \\
\text { of complex algebra. We } \\
\text { used MATLAB 2015a to } \\
\text { write down codes for the } \\
\text { evaluation of our case. }\end{array}$} \\
\hline Jan-17 & 9 & 202 & 4.4 & \\
\hline Feb-17 & 9 & 254 & 3.5 & \\
\hline Mar-17 & 12 & 379 & 3.1 & \\
\hline Apr-17 & 9 & 317 & 2.7 & \\
\hline Мау-17 & 7 & 310 & 2.1 & \\
\hline
\end{tabular}

The KPIs are used with their reference code as shown in Table 9. 


\begin{tabular}{lll}
$\begin{array}{lll}\text { Table 9: Key performance indicators (KPIs) } \\
\text { Key performance indicators }\end{array}$ & $\begin{array}{l}\text { Teference code } \\
\text { KPI } 1\end{array}$ & $\begin{array}{l}\text { Step } 1: \text { Table } 10 \\
\text { are as follows: }\end{array}$ \\
\hline Bed Turnover Rate (BTR) & KPI 2 & shows the secondary \\
Bed Occupancy Rate (BOR) & KPI 3 & data we obtained \\
Average Length of Stay (ALOS) & KPI 4 & from the hospital \\
Hospital Death Rate (HDR) & KPI 5 & authority. Five key
\end{tabular}

performance indicators from the data, namely Bed Turnover Rate (BTR), Average Length of Stay (ALOS), Bed Occupancy Rate (BOR), Hospital Death Rate (HDR), and Hospital Infection Rate (HIR), have been provided for this research.

\begin{tabular}{llllllll}
\multicolumn{3}{l}{ Table 10: Key performance indicator (KPI) data } & Step 2: We applied a first order \\
SL no & $\chi^{(0)}(1)$ & $\chi^{(0)}(2)$ & $\chi^{(0)}(3)$ & $\chi^{(0)}(4)$ & $\chi^{(0)}(5)$ & $\begin{array}{l}\text { weakening operator to Equations 8- } \\
12 \text { to smooth the indicator values }\end{array}$ \\
\hline KPI 1 & 6.5 & 7.9 & 8.6 & 9.2 & 9.8 & (see Table 11$)$. To further smooth \\
KPI 2 & 0.81 & 0.87 & 0.9 & 0.925 & 0.943 & out the values, we applied second \\
KPI 3 & 12.8 & 11.6 & 9.8 & 9.2 & 8.5 & order weakening operators to \\
KPI 4 & 3.3 & 2.8 & 2.6 & 2.1 & 1.8 & Equations $13-15$ to make our \\
KPI 5 & 4.4 & 3.5 & 3.1 & 2.7 & 2.1 & predictions more reliable and
\end{tabular}
accurate (see Table 12).

Table 11: Data sequence of first order weakening operator
\begin{tabular}{llllll} 
SL no & $\chi^{(0)}(1) f$ & $\chi^{(0)}(2) f$ & $\chi^{(0)}(3) f$ & $\chi^{(0)}(4) f$ & $\chi^{(0)}(5) f$ \\
\hline KPI 1 & 8.4000 & 8.8751 & 9.2 & 9.5 & 9.8 \\
KPI 2 & 0.8896 & 0.9095 & 0.9227 & 0.9340 & 0.943 \\
KPI 3 & 10.3800 & 9.7750 & 9.1667 & 8.8501 & 8.5 \\
KPI 4 & 2.5210 & 2.3250 & 2.1667 & 1.9500 & 1.8 \\
KPI 5 & 3.1600 & 2.8500 & 2.6333 & 2.4000 & 2.1
\end{tabular}




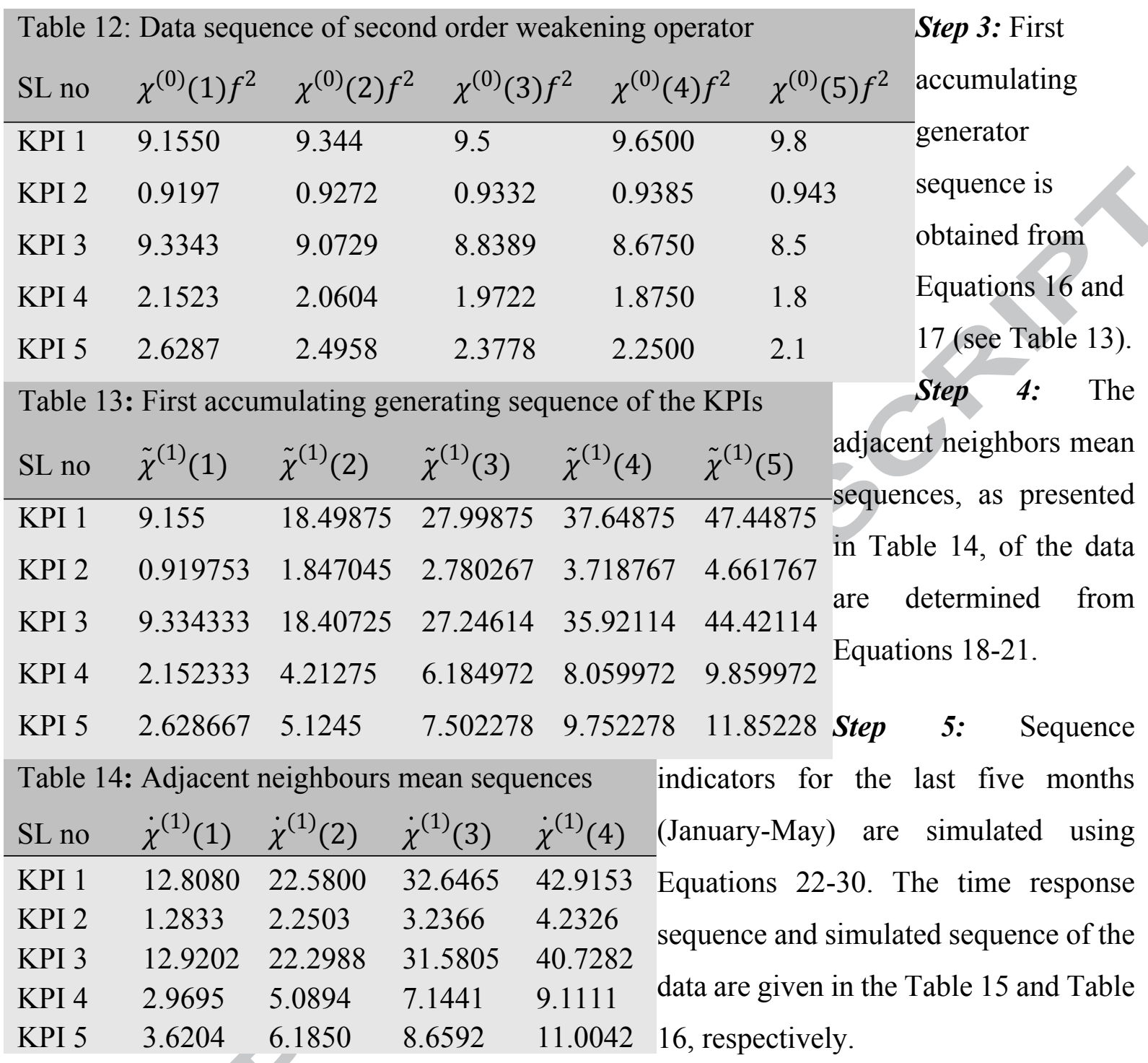

Table 15: Data sequence of time response

$\begin{array}{lllllll}\text { SL no. } & \hat{\chi}^{(1)}(1) & \hat{\chi}^{(1)}(2) & \hat{\chi}^{(1)}(3) & \hat{\chi}^{(1)}(4) & \hat{\chi}^{(1)}(5) & \text { Step 6: Five measures of } \\ \text { KPI 1 } & 9.1550 & 18.5180 & 28.0237 & 37.6743 & 47.4719 & \text { errors are calculated using } \\ \text { KPI 2 } & 0.9198 & 1.8480 & 2.7812 & 3.7193 & 4.66249 & \text { Equations 31-47; the values } \\ \text { KPI 3 } & 9.3343 & 18.3704 & 27.2248 & 35.9011 & 44.4029 & \text { are presented in Tables 17, } \\ \text { KPI 4 } & 2.1523 & 4.2034 & 6.1683 & 8.0507 & 9.85401 & \\ \text { KPI 5 } & 2.6287 & 5.1203 & 7.4824 & 9.7219 & 11.8451 & 18,19,20,21 \text { and 22. }\end{array}$

Table 16: Simulated sequence of the data

\begin{tabular}{llllll} 
SL no. & $\hat{\chi}^{(0)}(1)$ & $\hat{\chi}^{(0)}(2)$ & $\hat{\chi}^{(0)}(3)$ & $\hat{\chi}^{(0)}(4)$ & $\hat{\chi}^{(0)}(5)$ \\
\hline KPI 1 & 9.1550 & 9.3630 & 9.5057 & 9.6506 & 9.79764 \\
KPI 2 & 0.9198 & 0.9282 & 0.9332 & 0.9382 & 0.94317 \\
KPI 3 & 9.3343 & 9.0361 & 8.8544 & 8.6763 & 8.50183 \\
KPI 4 & 2.1523 & 2.0511 & 1.9649 & 1.8824 & 1.80332 \\
KPI 5 & 2.6287 & 2.4916 & 2.3622 & 2.2395 & 2.1232
\end{tabular}




Table 17: Sequential data of estimated errors
\begin{tabular}{lllllll} 
SL no. & $\varepsilon^{(0)}(1)$ & $\varepsilon^{(0)}(2)$ & \multicolumn{1}{c}{$\varepsilon^{(0)}(3)$} & $\varepsilon^{(0)}(4)$ & $\varepsilon^{(0)}(5)$ \\
\hline KPI 1 & 0 & -0.0193 & -0.0057 & -0.0006 & 0.0024 \\
KPI 2 & 0 & -0.0009 & 0.0000 & 0.0003 & -0.0002 \\
KPI 3 & 0 & 0.0368 & -0.0155 & -0.0013 & -0.0018 \\
KPI 4 & 0 & 0.0094 & 0.0073 & -0.0074 & -0.0033 \\
KPI 5 & 0 & 0.0042 & 0.0156 & 0.0105 & -0.0232 \\
Table 18: Relative errors & & & \\
SL no. & \multicolumn{7}{c}{$\delta_{1}$} & \multicolumn{2}{c}{$\delta_{2}$} & \multicolumn{2}{c}{$\delta_{3}$} & $\delta_{4}$ & $\delta_{5}$ \\
\hline KPI 1 & 0 & 0.0021 & 0.0006 & 0.0001 & 0.0002 \\
KPI 2 & 0 & 0.0010 & 0.0000 & 0.0004 & 0.0002 \\
KPI 3 & 0 & 0.0041 & 0.0018 & 0.0002 & 0.0002 \\
KPI 4 & 0 & 0.0045 & 0.0037 & 0.0039 & 0.0018 \\
KPI 5 & 0 & 0.0017 & 0.0066 & 0.0047 & 0.0110
\end{tabular}

Table 19: Average relative error and filtering error

\begin{tabular}{lll} 
SL no. & Mean relative error & Filtering \\
\hline KPI 1 & 0.0006 & 0.00024 \\
KPI 2 & 0.0003 & 0.00018 \\
KPI 3 & 0.0012 & 0.00022 \\
KPI 4 & 0.0028 & 0.00184 \\
KPI 5 & 0.0048 & 0.01105
\end{tabular}

Table 20: Absolute value degree of grey sequence incidences $(\epsilon>0.90)$

\begin{tabular}{lcccccc} 
SL no. & $|s|$ & \multicolumn{1}{c}{$s$} & \multicolumn{1}{c}{$|\hat{s}|$} & \multicolumn{1}{c}{$\hat{s}$} & $|\hat{s}-s|$ & $\epsilon$ \\
\hline KPI 1 & 1.3513 & 1.3513 & 1.3756 & 1.3756 & 0.0243 & 0.9935 \\
KPI 2 & 0.0514 & 0.0514 & 0.0520 & 0.0520 & 0.0006 & 0.9994 \\
KPI 3 & 1.8334 & -1.8334 & 1.8525 & -1.8525 & 0.0191 & 0.9959 \\
KPI 4 & 0.7255 & -0.7255 & 0.7332 & -0.7332 & 0.0076 & 0.9969 \\
KPI 5 & 1.0267 & -1.0267 & 1.0455 & -1.0455 & 0.0187 & 0.9939
\end{tabular}




\begin{tabular}{|c|c|c|c|c|c|}
\hline SL no. & $\bar{\chi}$ & $S_{1}^{2}$ & $\bar{\varepsilon}$ & $S_{2}^{2}$ & C \\
\hline KPI 1 & 9.4898 & 0.0511 & -0.0046 & 0.0001 & 0.0344 \\
\hline KPI 2 & 0.9324 & 0.0001 & -0.0001 & 0.0000 & 0.0519 \\
\hline KPI 3 & 8.8842 & 0.0863 & 0.0036 & 0.0003 & 0.0596 \\
\hline KPI 4 & 1.9720 & 0.0159 & 0.0012 & 0.0000 & 0.0501 \\
\hline KPI 5 & 2.3705 & 0.0340 & 0.0014 & 0.0002 & 0.0727 \\
\hline
\end{tabular}

Table 22: Check value and little error probability $(p>0.95)$

\begin{tabular}{llllllll} 
SL no. & $\varepsilon^{(0)}(1)-\bar{\varepsilon}$ & $\varepsilon^{(0)}(1)-\bar{\varepsilon}$ & $\varepsilon^{(0)}(1)-\bar{\varepsilon}$ & $\varepsilon^{(0)}(1)-\bar{\varepsilon}$ & $\varepsilon^{(0)}(1)-\bar{\varepsilon}$ & $\begin{array}{l}\text { Check } \\
\text { value }\end{array}$ & $\begin{array}{l}P \\
\text { value }\end{array}$ \\
\hline KPI 1 & 0.0046 & 0.0146 & 0.0011 & 0.0041 & 0.0070 & 0.1526 & 1 \\
KPI 2 & 0.0001 & 0.0008 & 0.0002 & 0.0005 & 0.0000 & 0.0055 & 1 \\
KPI 3 & 0.0036 & 0.0332 & 0.0191 & 0.0050 & 0.0055 & 0.1983 & 1 \\
KPI 4 & 0.0012 & 0.0082 & 0.0061 & 0.0086 & 0.0045 & 0.0850 & 1 \\
KPI 5 & 0.0014 & 0.0028 & 0.0142 & 0.0091 & 0.0246 & 0.1245 & 1
\end{tabular}

Step 7: Simulated time response sequence and simulated sequence for the next five months are obtained using Equations 48 (see Tables 23 and 24).

Table 23: Prediction of time responses for the next five periods

$\begin{array}{llllllll}\text { SL no. } & \hat{\chi}^{(1)}(6) & \hat{\chi}^{(1)}(7) & \hat{\chi}^{(1)}(8) & \hat{\chi}^{(1)}(9) & \hat{\chi}^{(1)}(10) & \text { Sensitivity analysis is } \\ \text { KPI 1 } & 57.4189 & 67.5174 & 77.7699 & 88.1786 & 98.7459 & \text { done to ensure the } \\ \text { KPI 2 } & 5.6107 & 6.56397 & 7.52233 & 8.48582 & 9.45444 & \text { robustness of the model } \\ \text { KPI 3 } & 52.7338 & 60.8971 & 68.8963 & 76.7346 & 84.4153 & & \text { (Schmidt and Finan, } \\ \text { KPI 4 } & 11.5816 & 13.2366 & 14.8221 & 16.341 & 17.7961 & & \\ \text { KPI 5 } & 13.8581 & 15.7665 & 17.5758 & 19.2911 & 20.9173 & & 2018 \text {, Civan, 2007). The }\end{array}$
Table 24: Predicted values of KPIs for the next five periods

$\begin{array}{llllllll}\text { SL no. } & \hat{\chi}^{(0)}(6) & \hat{\chi}^{(0)}(7) & \hat{\chi}^{(0)}(8) & \hat{\chi}^{(0)}(9) & \hat{\chi}^{(0)}(10) & \text { based on manipulating } \\ \text { KPI 1 } & 9.94696 & 10.0986 & 10.2525 & 10.4087 & 10.5673 & \text { different parameters is done } \\ \text { KPI 2 } & 0.94821 & 0.95327 & 0.95836 & 0.96348 & 0.96863 & \text { in sensitivity analysis to } \\ \text { KPI 3 } & 8.33086 & 8.16333 & 7.99917 & 7.83831 & 7.68068 & & \\ \text { KPI 4 } & 1.72758 & 1.65502 & 1.5855 & 1.51891 & 1.45511 & \text { find out the model with } \\ \text { KPI 5 } & 2.01293 & 1.90839 & 1.80928 & 1.71532 & 1.62624 & \text { optimum parameter values }\end{array}$

(Liang, 2013). Adjacent neighbor means are calculated from Eq. (20) where $\varphi, \omega$ are the two parameters that we will tune to minimize mean relative error and filtering error. The range for the parameters was set at 0.1 to 0.9 , a total of 81 combinations was tested to find out the best combination that gives the minimum error. For example, $\varphi=0.1$ was kept constant while $\omega$ was varied from 0.1 to 0.9 . Each combination presents an increasing trend of error, and plotting all combinations generate a bell curve for each combination as the value drops when error 
values of a new combination starts. From Figure 2, the height of each curve depicts the maximum error length, and therefore, curve having the lower heights fulfil the error criteria.

Mean relative error with different combination of $(\square, \square)$

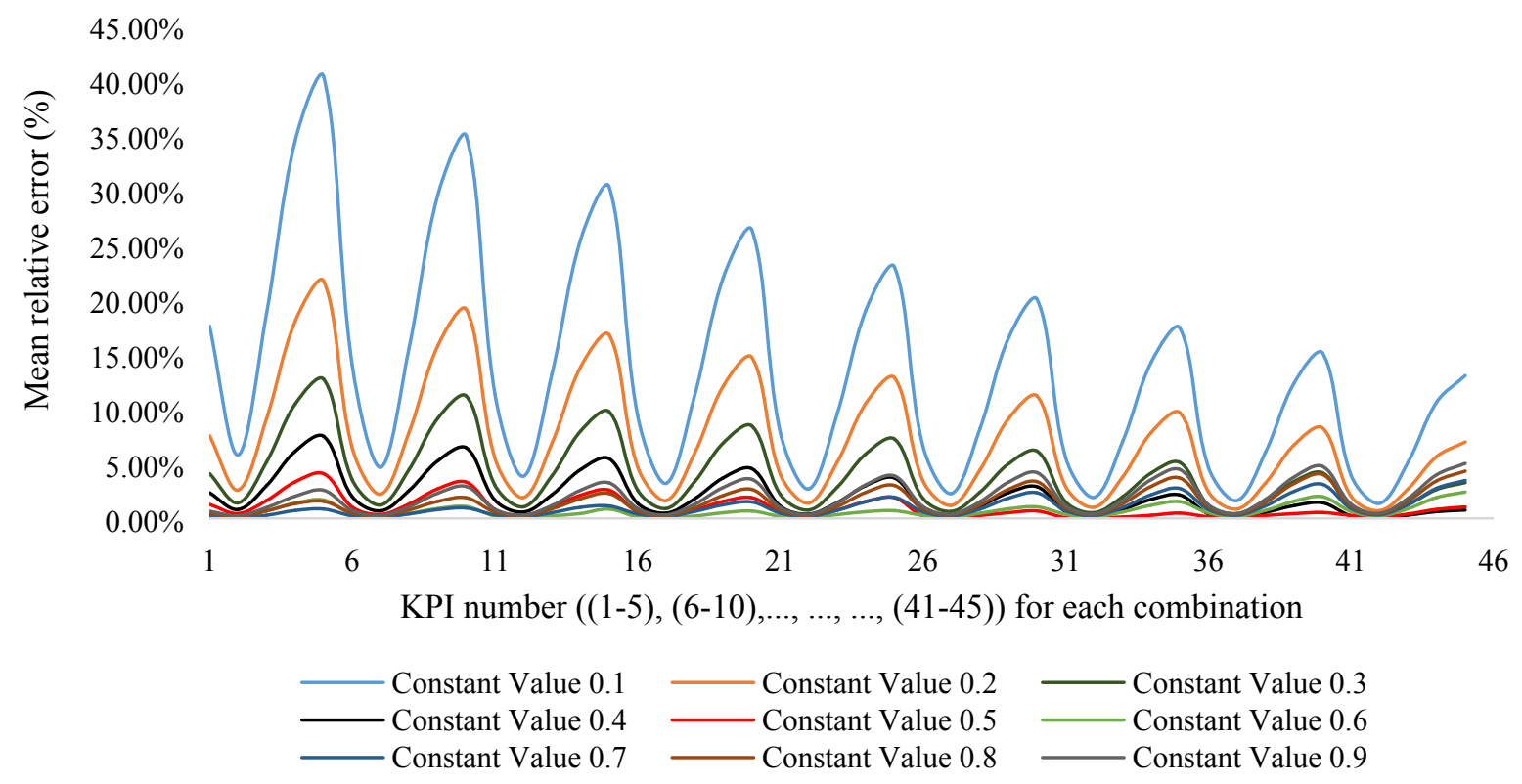

Figure 2: Sensitivity analysis

We set a threshold value of $2 \%$ for mean relative error and filtering error. Therefore, Figure 2 was re-plotted in Figure 3 by restricting $\mathrm{Y}$-axis value to $2 \%$ to have an insight of the combinations that satisfy the error condition.

Mean relative error with different combination of $(\square, \square)$
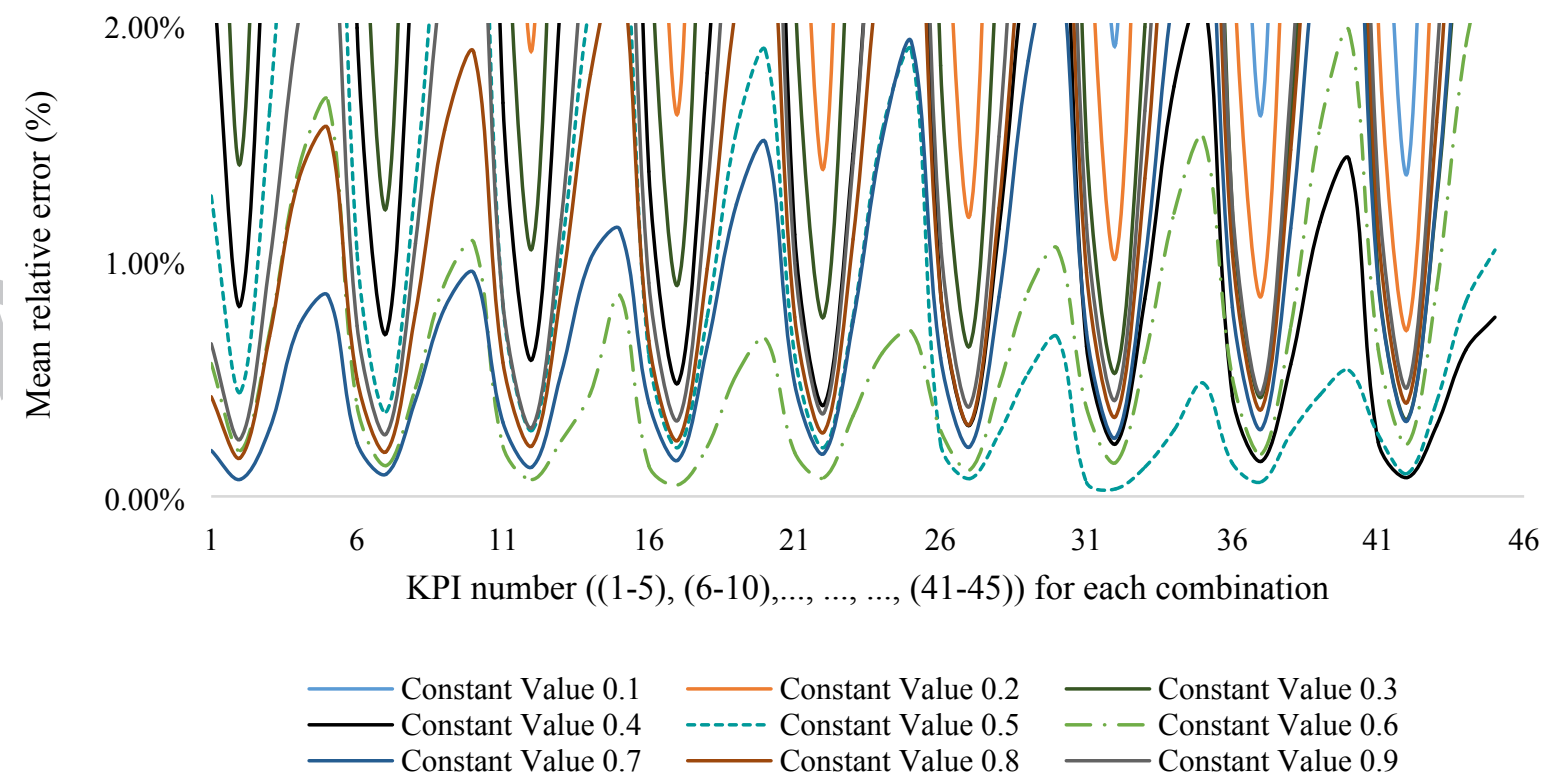

Figure 3: Sensitivity analysis, Y-axis restricted to threshold value 
From Figure 3, while $\varphi$ was kept constant at 0.5 and 0.6 and $\omega$ was varied, we found considerably low mean relative error. The combinations of $(0.5,0.1),(0.5,0.2),(0.5,0.3)$ and $(0.6,0.9)$ failed to satisfy error condition (see Figure 4 below and Table A1 in Appendix section).

Mean relative error for constant values of 0.5 and 0.6

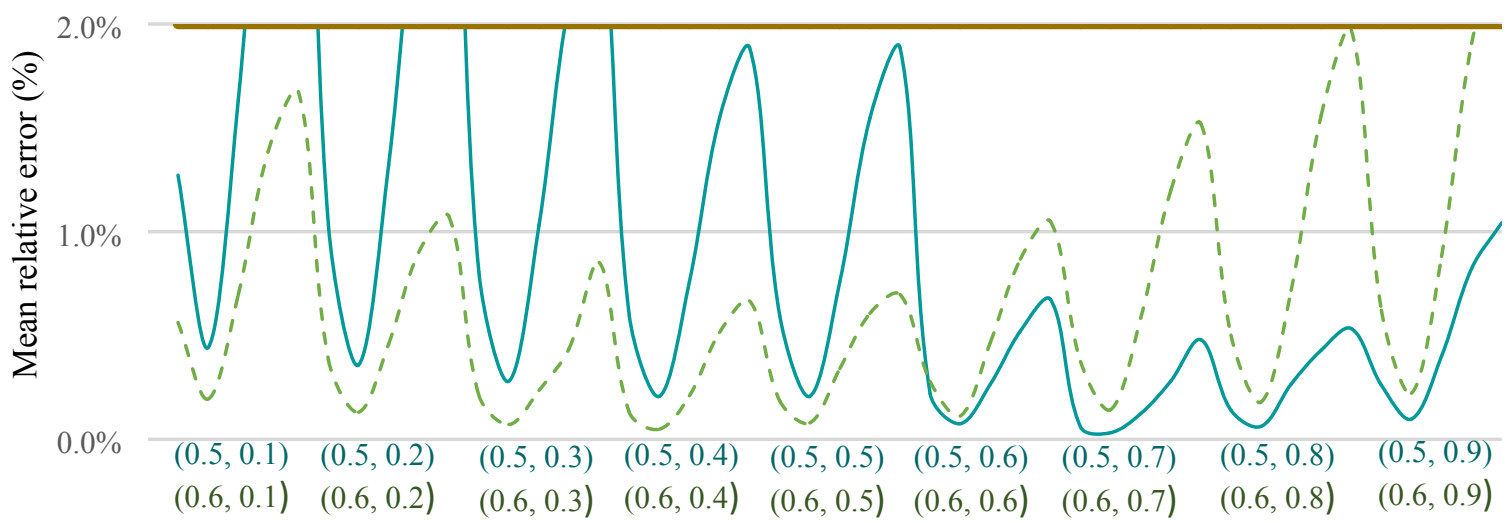

Different combinationis of $(\square, \square)$

— Constant Value $0.5----$ Constant Value $0.6 \longrightarrow$ Threshold Value

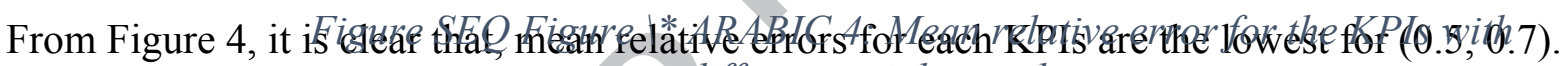
Therefore, $(\varphi, \omega)=(0.5,0.7)$ is chosen as optimized parameters for the model.

\subsection{Model Comparison}

Different forecasting models can be compared with our proposed model. However, moving average, exponential smoothing and linear regression are the most popular methods to implement a time series forecasting model (Guidolin and Pedio, 2018). We have compared all these models and found that linear regression gave a reasonable outcome. Linear regression is useful in determining the relationships between two continuous variables, and it is one of the most commonly used basic types of predictive model (Schmidt and Finan, 2018). Selecting the right number of cases has been a dilemma for establishing a linear regression model with less bias. Several rule-of-thumb have been given by many researchers. Austin and Steyerberg (2015) suggested that a minimum of two samples per variable is enough to make a regression analysis with a relative bias of less than $10 \%$, and it is sufficient to determine adequate estimation of regression coefficients. Increasing the sample number provides higher coefficient of correlation, and thus increases data fitting of the model. Green (1991) suggested that minimum number of subjects for each predictor should be 5 to make a prediction model using 
linear regression. In linear regression, a new value is calculated using the following equation of straight line-

$\hat{\chi}_{p}^{(0)}(k)=a+b u_{\mathrm{k}}(49)$

$a=\frac{1}{m}\left(\sum_{k=1}^{m} \hat{\chi}^{(0)}(k)-\sum_{k=1}^{m} u_{\mathrm{k}}\right)(50)$

$b=\frac{\sum\left(u_{\mathrm{k}}-\frac{1}{m} \sum_{k=1}^{m} u_{\mathrm{k}}\right)\left(\hat{\chi}_{a}^{(0)}(k)-\frac{1}{m} \sum_{k=1}^{m} \hat{\chi}_{a}^{(0)}(k)\right)}{\sum\left(u_{\mathrm{k}}-\sum_{k=1}^{m} u_{\mathrm{k}}\right)^{2}}(51)$

Here,

$\hat{\chi}_{a}^{(0)}(k)=$ Actual known values of the KPIs

$\hat{\chi}_{p}^{(0)}(k)=$ Predicted values of the KPIs

$u_{\mathrm{k}}=$ Corresponding time period $($ January $=1$, February $=2 \ldots \ldots$ May $=5)$

We developed the linear regression model using Excel 2016 and used FORECAST function. Multiple linear regression model fits our data very well as depicted in Figure 5. Several statistical error measurement technique are available to measure the accuracy of a prediction model. Since, all the actual and forecasted data are positive and are greater than zero, we used mean absolute percent error (MAPE) and relative percent error (RPE) for simplicity (Hyndman and Koehler, 2006). RPE and mean absolute percentage of error MAPE are calculated for this model using the following formulae:

$$
\begin{aligned}
& R P E=\frac{\left|\hat{\chi}_{a}^{(0)}(k)-\hat{\chi}_{p}^{(0)}(k)\right|}{\hat{\chi}_{a}^{(0)}(k)} \times 100 \%(52) \\
& M A P E=\left(\frac{1}{m} \sum_{k=1}^{m} \frac{\left|\hat{\chi}_{a}^{(0)}(k)-\hat{\chi}_{p}^{(0)}(k)\right|}{\hat{\chi}_{a}^{(0)}(k)}\right) \times 100 \%(53)
\end{aligned}
$$




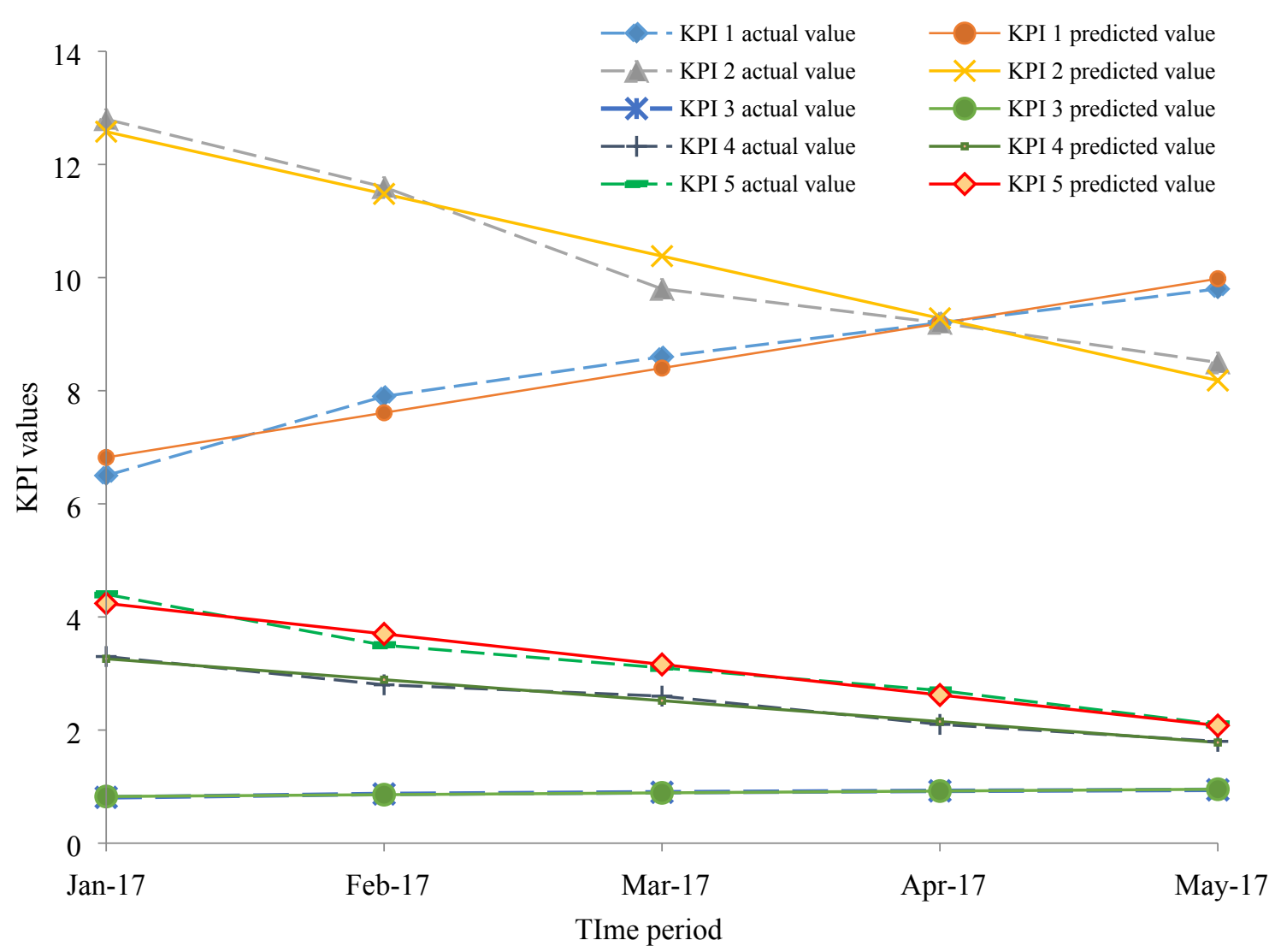

Figure 5: Data fitting of linear regression model

KPI 1 and KPI 3 show strong positive linear correlation between the datasets whereas KPI 2, KPI 4 and KPI 5 show strong negative linear correlation between the datasets. As our considered datasets are linearly correlated, it is evident from Table 25 that model with lower percentage of error should be chosen to make this prediction model. A comparison between GM $(1,1)$ and linear regression is presented in Table 25,

\section{Table 25: Comparison of MAPE between $G M(1,1)$ model and linear regression model}

$\begin{array}{lllllll}\begin{array}{l}\text { Error criterion } \\ \text { KPIs }\end{array} & \text { MAPE } & & & & & \begin{array}{l}\text { From Table 25, it is } \\ \text { evident that GM }(1,\end{array} \\ & \text { BTR } & \text { BOR } & \text { ALOS } & \text { HDR } & \text { HIR } & \text { 1) model has much } \\ \text { LM }(1,1) & 0.06 \% & 0.03 \% & 0.12 \% & 0.28 \% & 0.48 \% & \text { lower percentage } \\ \text { Linear regression } & 2.57 \% & 2.66 \% & 1.20 \% & 2.20 \% & 3.04 \% & \begin{array}{l}\text { of error than linear }\end{array}\end{array}$
regression approach. Grey model can conduct forecasting efficiently without data distribution information or large sample size (Qian Wang et al., 2014) and data fitting in GM $(1,1)$ model is higher because of higher coefficient of correlations.

\subsection{Model Evaluation}


The result of our prediction model were validated by a panel of experts consisting of six members. They judged the model and rated it on a five point scale varying from excellent to very poor, as shown in Table 26 . Their responses were converted into grey scale using the conversion scale as shown in Table 27. Grey average values were converted using mean value whitening (Deng, 1989) and averaged with equal weight. In the view of the analysts, the indicator values seem realistic and do not deviate much from actual values based on a threshold of 0.5 .

Table 26: Grey values for the assessment

\begin{tabular}{llll} 
Linguistic representation & Corresponding grey values & $\begin{array}{l}\text { 5. Results } \\
\text { discussion }\end{array}$ \\
\hline Very Inaccurate (VI) & $(0,2)$ & and \\
Inaccurate (I) & $(2,4)$ & Health information \\
Moderate Accuracy (MA) & $(4,6)$ & technology (Health IT) \\
Good Accuracy (GA) & $(6,8)$ & supports & mealth \\
Excellent Accuracy (EA) & $(8,10)$ & manement systems \\
\hline
\end{tabular}

Table 27: Crisp value and evaluation results

\begin{tabular}{|c|c|c|c|c|c|c|c|c|}
\hline Indicators & $\begin{array}{l}\text { Expert } \\
1\end{array}$ & $\begin{array}{l}\text { Expert } \\
2\end{array}$ & $\begin{array}{l}\text { Expert } \\
3\end{array}$ & $\begin{array}{l}\text { Expert } \\
4\end{array}$ & $\begin{array}{l}\text { Expert } \\
5\end{array}$ & $\begin{array}{l}\text { Expert } \\
6\end{array}$ & $\begin{array}{l}\text { Average } \\
\text { grey value }\end{array}$ & $\begin{array}{l}\text { Crisp } \\
\text { value }\end{array}$ \\
\hline$\overline{\mathrm{BTO}}$ & {$[8,10]$} & {$[6,8]$} & {$[6,8]$} & {$[8,10]$} & {$[8,10]$} & {$[6,8]$} & {$[7,9]$} & 8 \\
\hline ALOS & {$[6,8]$} & {$[8,10]$} & {$[6,8]$} & {$[8,10]$} & {$[8,10]$} & {$[8,10]$} & {$[7.33,9.33]$} & 8.33 \\
\hline BOR & {$[6,8]$} & {$[6,8]$} & {$[8,10]$} & {$[6,8]$} & {$[6,8]$} & {$[8,10]$} & {$[6.67,8.33]$} & 7.5 \\
\hline HDR & {$[6,8]$} & {$[6,8]$} & {$[8,10]$} & {$[6,8]$} & {$[6,8]$} & {$[8,10]$} & {$[6.67,8.67]$} & 7.67 \\
\hline HIR & {$[6,8]$} & {$[8,10]$} & {$[8,10]$} & {$[8,10]$} & {$[8,10]$} & {$[6,8]$} & {$[7.33,9.33]$} & 8.33 \\
\hline
\end{tabular}

sharing between consumers, payers, and quality monitors. Hospital or healthcare facilities in Bangladesh do not publish these data in a public domain for research. The process of collecting healthcare data has some limitations as data are only collected for service improvement purposes, to ensure compliance with civil rights provisions. Moreover, analyzing a large amount of data is time-consuming and sometimes produces inaccurate results. Selecting and analyzing the correct indicators with the right amount of data can produce a good result and improve decision-making capabilities. The source of data available to us here was unknown, hence choosing grey theory to analyze the data. Grey theory works best when data is not referred to a source, which adds uncertainty. The future value of the selected key performance indicators (KPIs) can be predicted using the GM $(1,1)$ model. 
The methodology described in section 3 was evaluated by analyzing a case study of a hospital in Bangladesh. The secondary data collected was considered as raw data and representative KPIs were used as inputs from months January 2017- May 2017. We analyzed the data using an improved grey prediction model. The simulated values were checked to ensure better accuracy using five measures of error, as presented in section 3, step 6 . The errors are within the threshold limit so the simulated data can be conceived as a true sequence of the periodic KPIs; therefore, the model represents an actual evaluation of the data in the system. We used this model to predict values of the next five periodic values of KPIs from June-October, 2017. Data with increasing or decreasing trends fit well in the grey prediction model. As the data sources are unknown, we applied buffer operators to remove possible distortions in the data. Successive application of first order and second order weakening operators smooth data, which is visible in Figures 6,7 and 8. Variations in the data are affected after applying weakening operators. A clearer common trend is visible after using an accumulating generator operator, as even raw data show increasing or decreasing evolution. The first aggregated generator sequence in the data is provided in Figure 9. Stochastic fluctuation in the original data series was weakened by applying the aggregated generator operator, with the result representing the inherent nature of the data. The mean generator sequence of the data was calculated to smoothen the values, as shown in Figure 10. A new method of constructing the data sequence as made by applying a mean generator operator when there is missing data in the system. Figures 9 and 10 show similarity in their trends, although their values changed when we took the mean value of the 1-AGO sequence, due to our ignorance of missing data. 


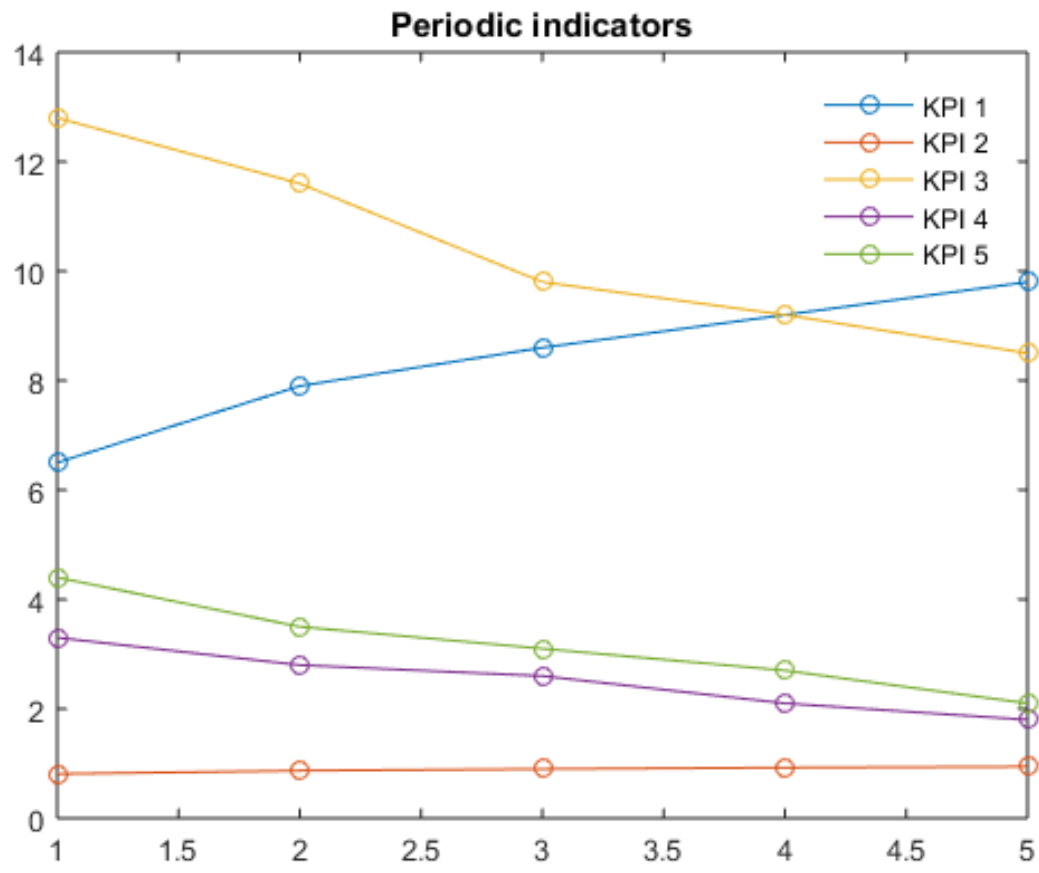

Figure 6: Periodic KPI values

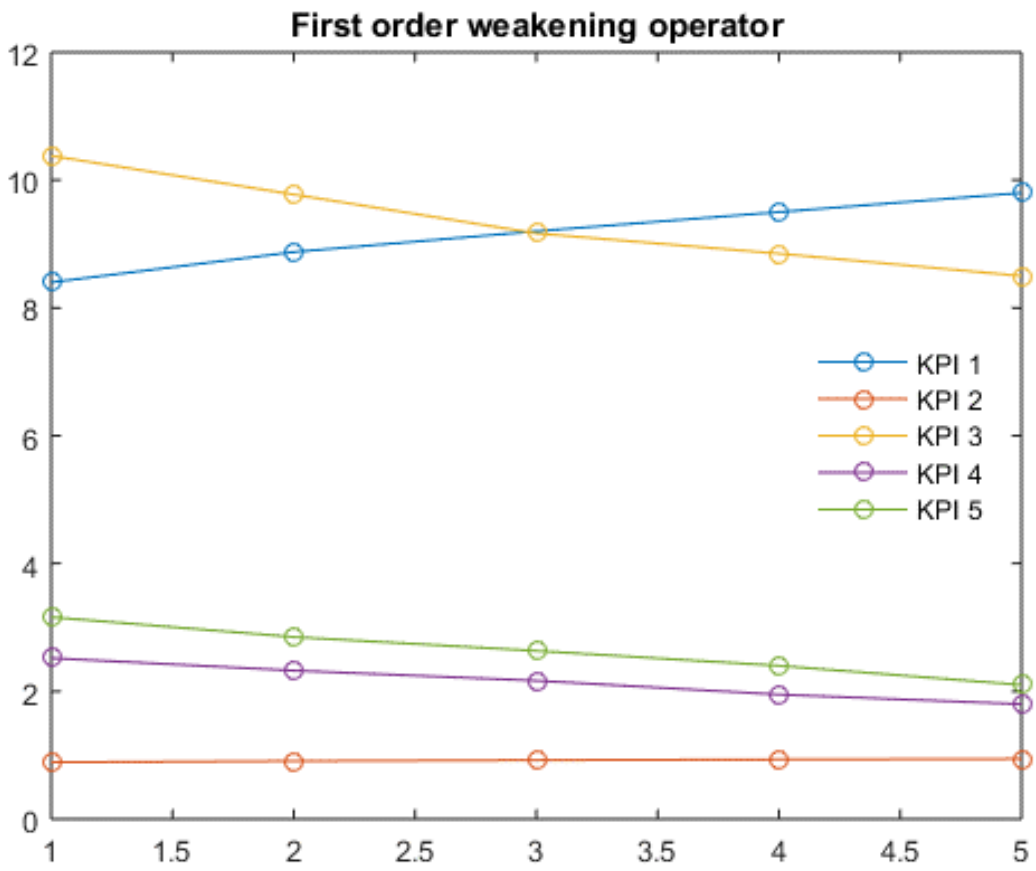

Figure 7: First order weakening of KPI values 


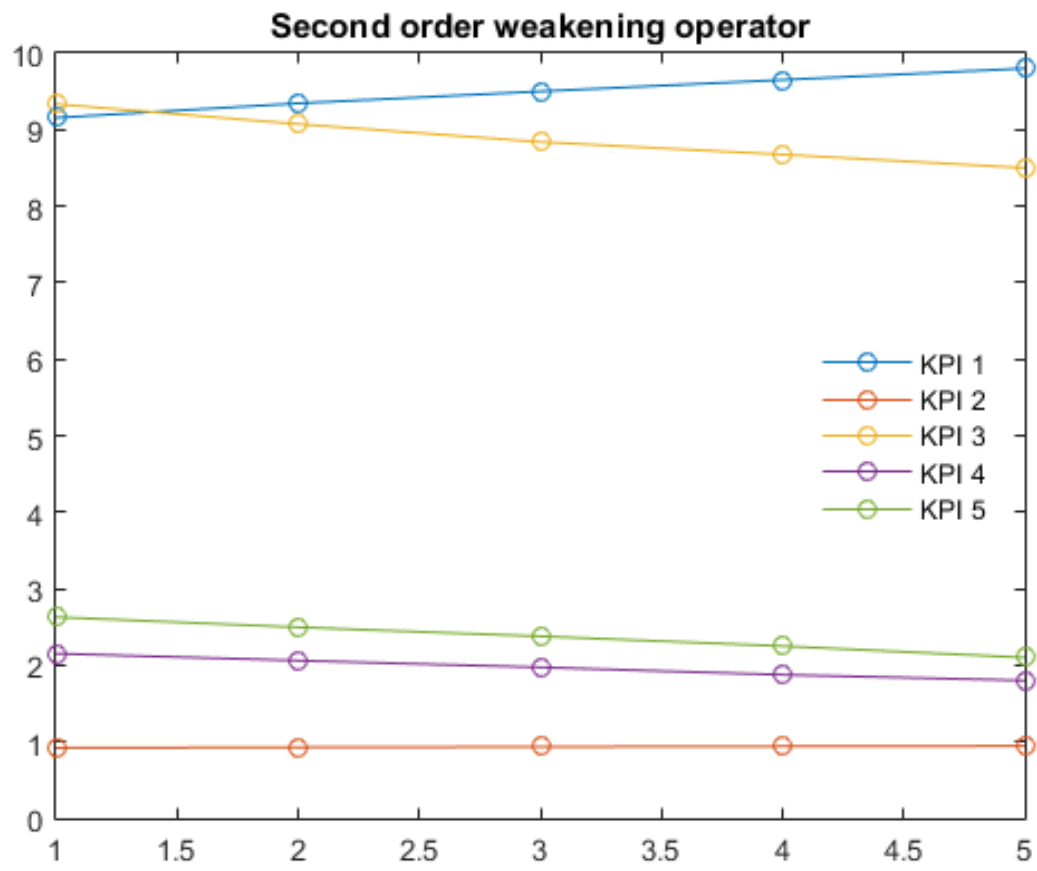

Figure 8: Second order weakening of KPI values

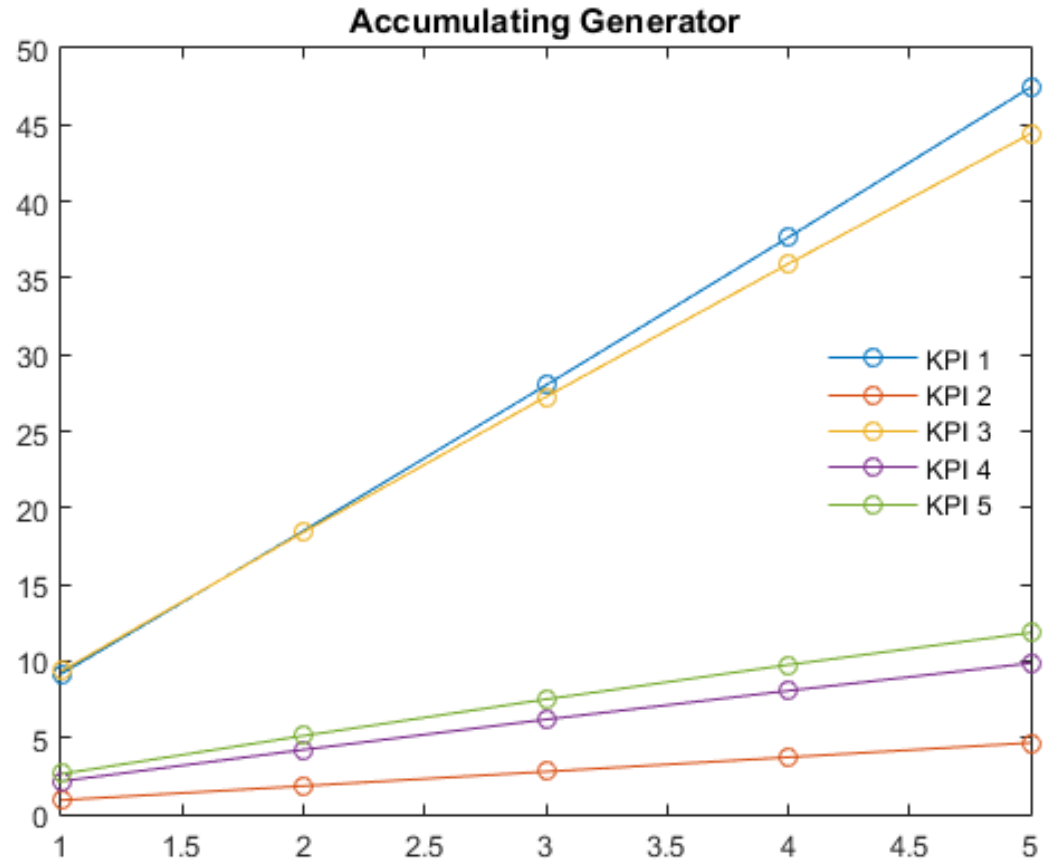

Figure 9: 1-AGO sequence of KPIS 


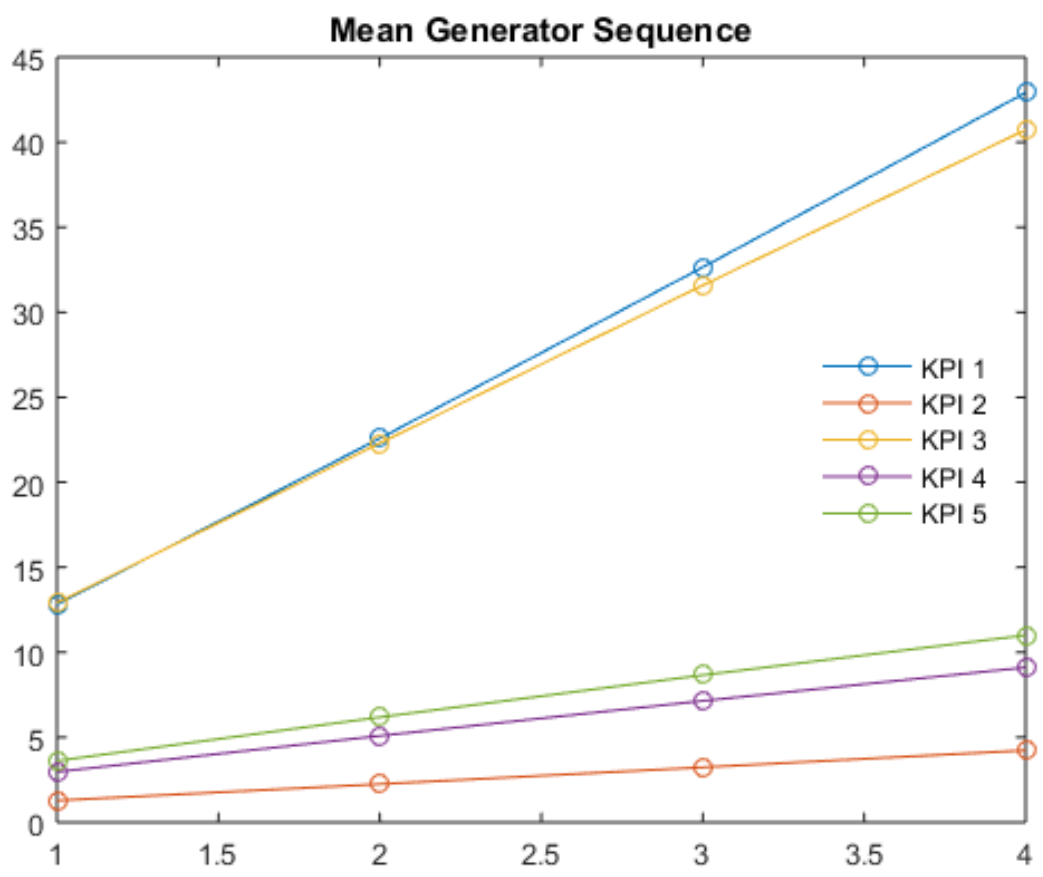

Figure 10: Mean generator sequence of KPIs

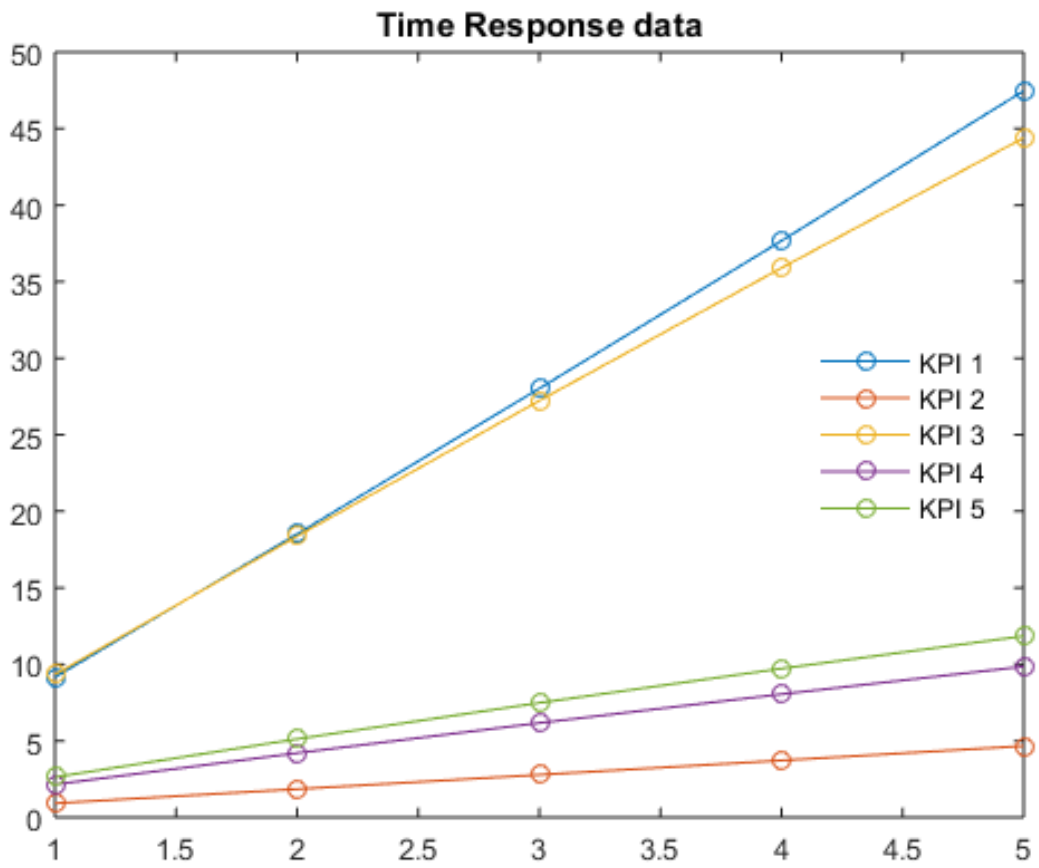

Figure 11: Time response sequence of KPI values

We obtained aggregate time response sequences for the concerned time period from the simulation shown in Figure 11; a simulated sequence of the data is shown in Figure 12. From Figure 12, it is clear that the simulated data sequence shows similarity with the data sequence 
obtained by applying a second order weakening operator; therefore, the model has a lower probability of fitting errors. The predicted values for the KPIs are shown in Figures 13 and 14. Figure 14 shows the true representation of the key performance indicators sequence for the next five months; hence, the model seems to understand the nature of the system and our prediction model is reliable.
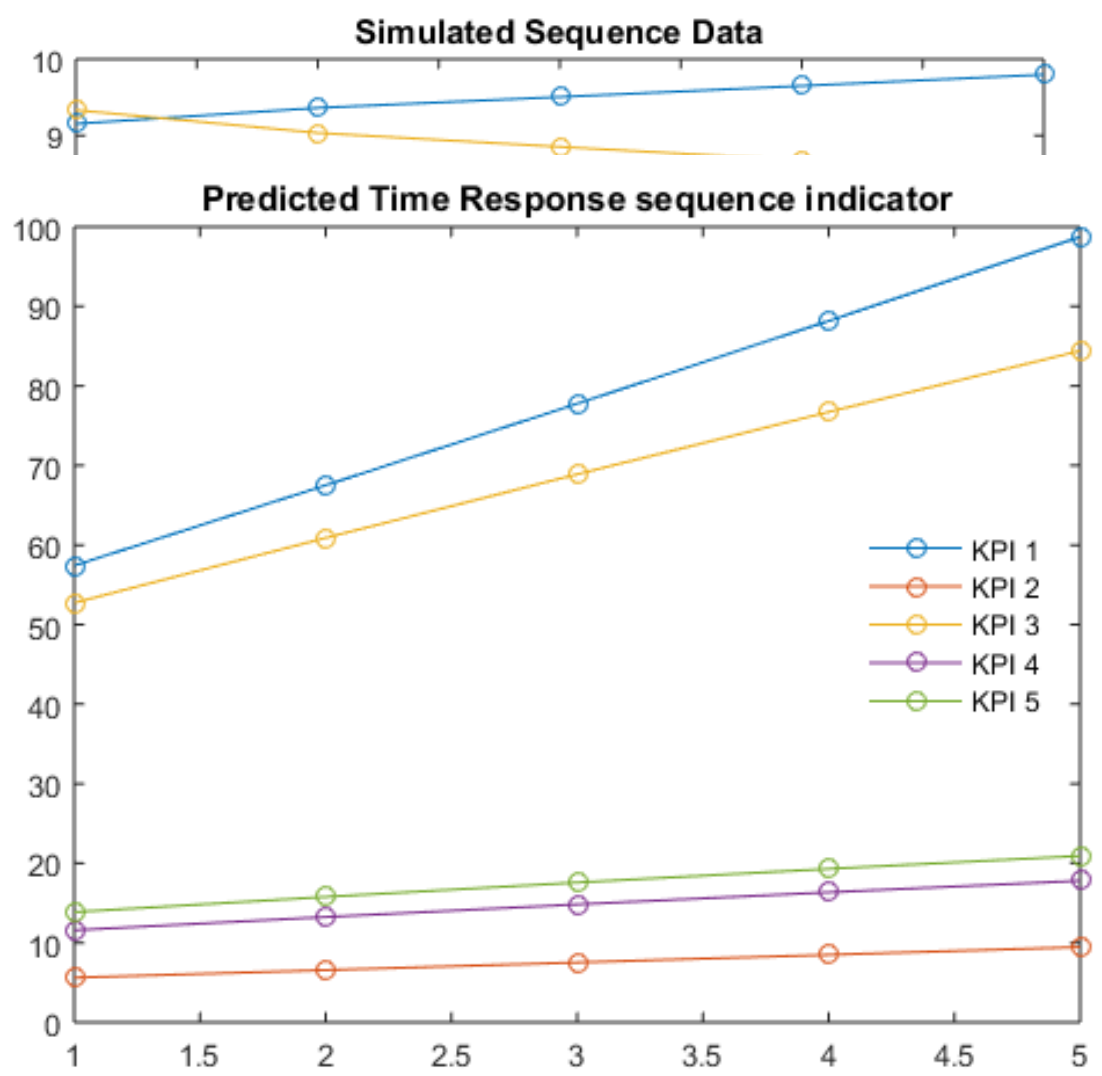

Figure 13: Predicted time response sequence of KPI values 
Error measurement has been checked by comparing the simulated values and actual values of the KPIs. Estimated errors are shown in Figure 15 and the relative errors are presented in Figure 16. From Figure 15, KPI 3 and KPI 5 generate large sequential error in the dataset; however, KPI 3 produces a small relative error, which is shown in Figure 16.

We set a threshold limit of 0.02 for the mean relative error and filtering error. Figure 17 shows that the errors are well below the threshold value; hence, they achieve Level 1 for prediction. The absolute degree of grey incidences are much higher than the check value, as shown in Figure 18, which means the model is effective in analysing grey sequence incidence. From Figure 18, it is visible that the absolute degree of grey incidences are closer to 1 for all the KPIs, which guarantees all the KPIs are changing their magnitude the same amount. From Table 3, a small error probability and variance ratio of $>0.95$ and $<0.35$ is needed, respectively, for excellent prediction. From Figure 19 and Figure 20, it is seen that both the terms satisfy the condition to achieve Level 1; therefore, our model generates a lower margin of error. The model

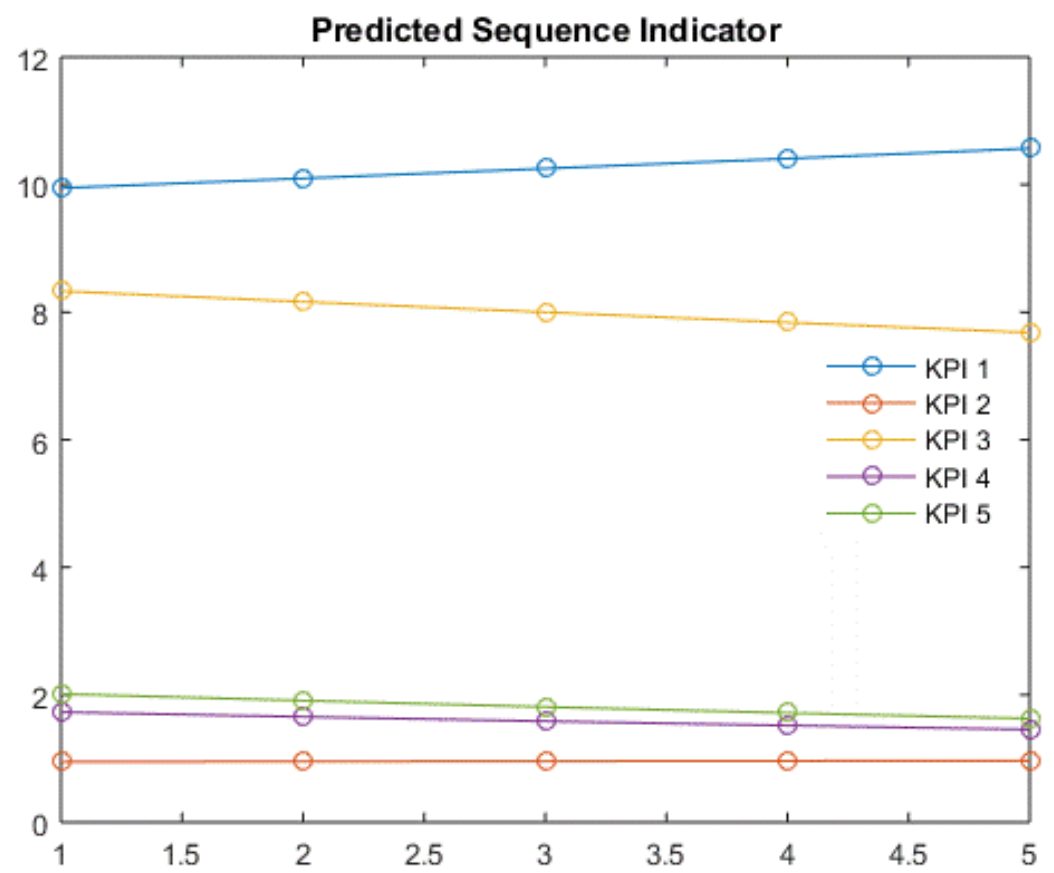

Figure 14: Predicted values for the next five periods

is very satisfactory in terms of precision. 


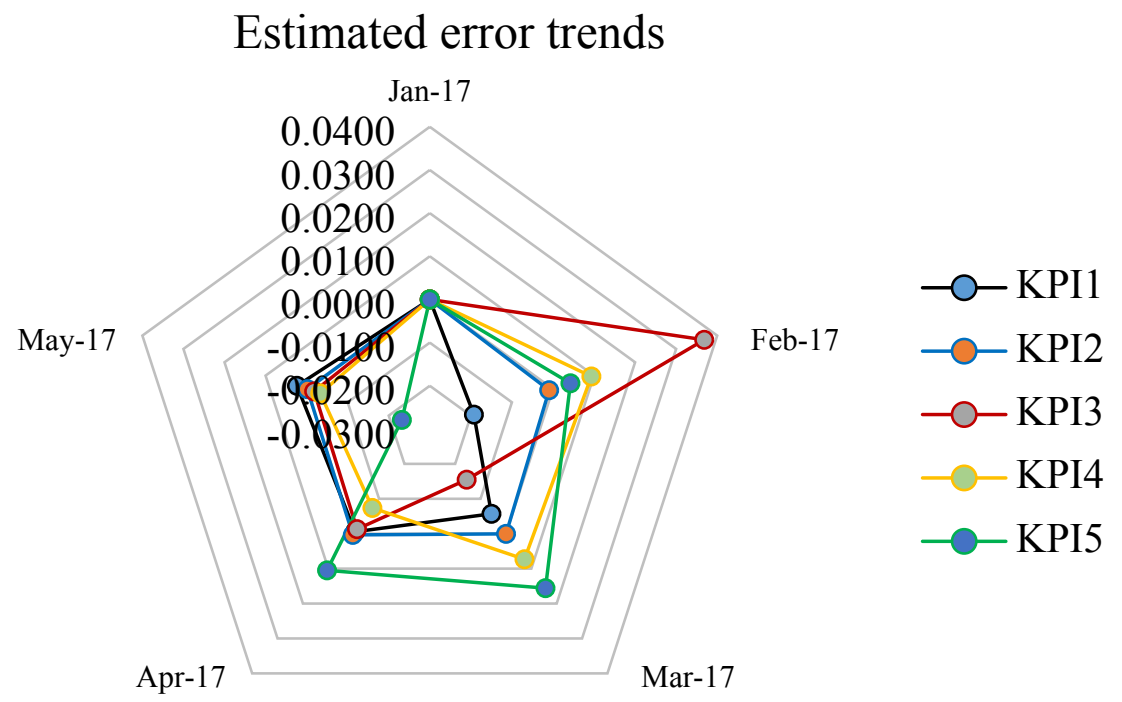

Figure 15: Estimated errors of simulated data sequence

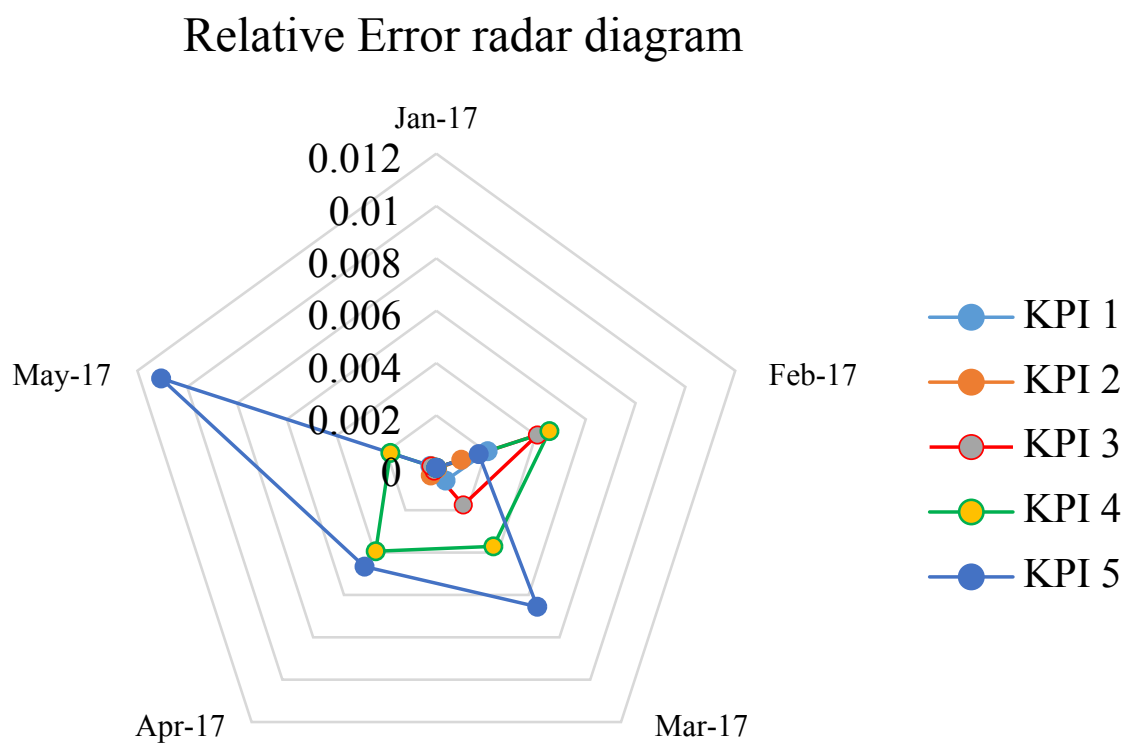

Figure 16: Sequential relative errors of simulated data 


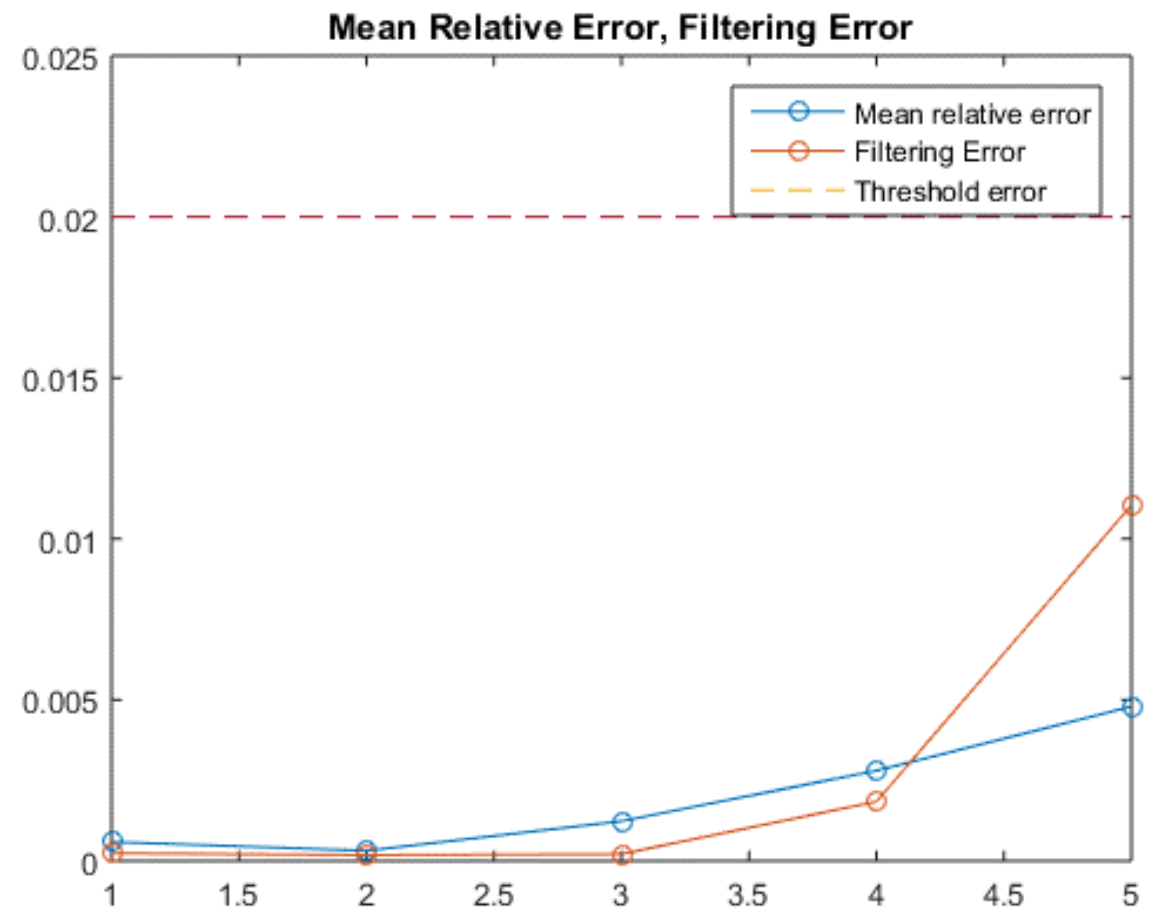

Figure 17: Filtering and mean relative error with check value

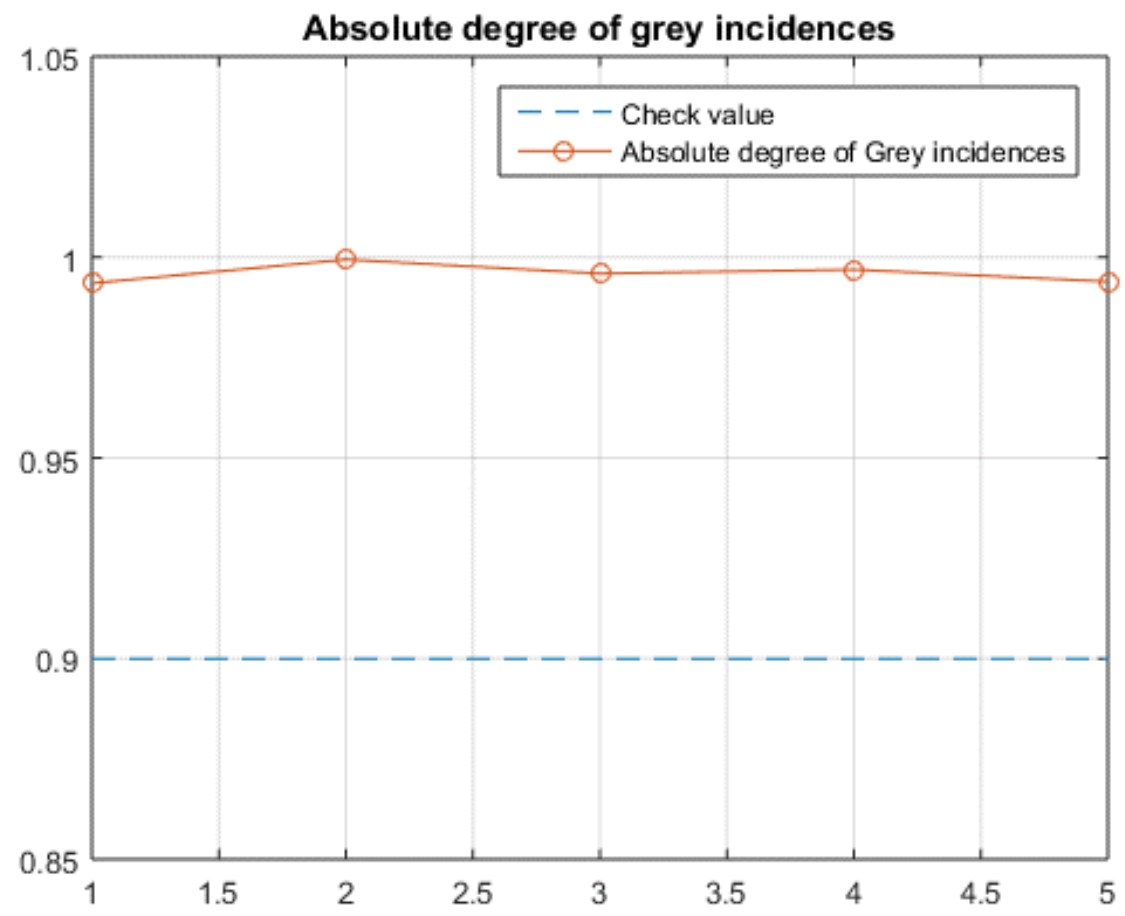

Figure 18: Absolute degree of grey incidences of the data sequence 


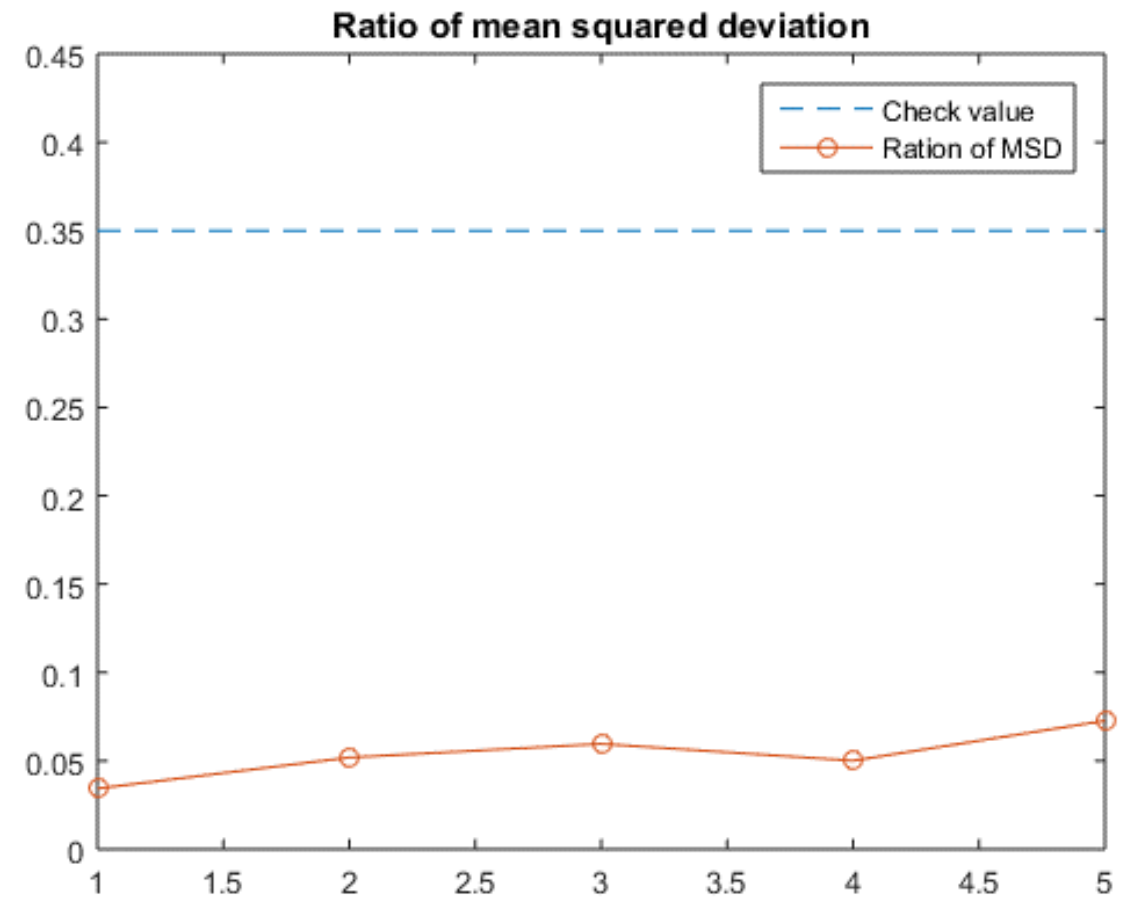

Figure 19: Ration of mean squared deviations of data sequence

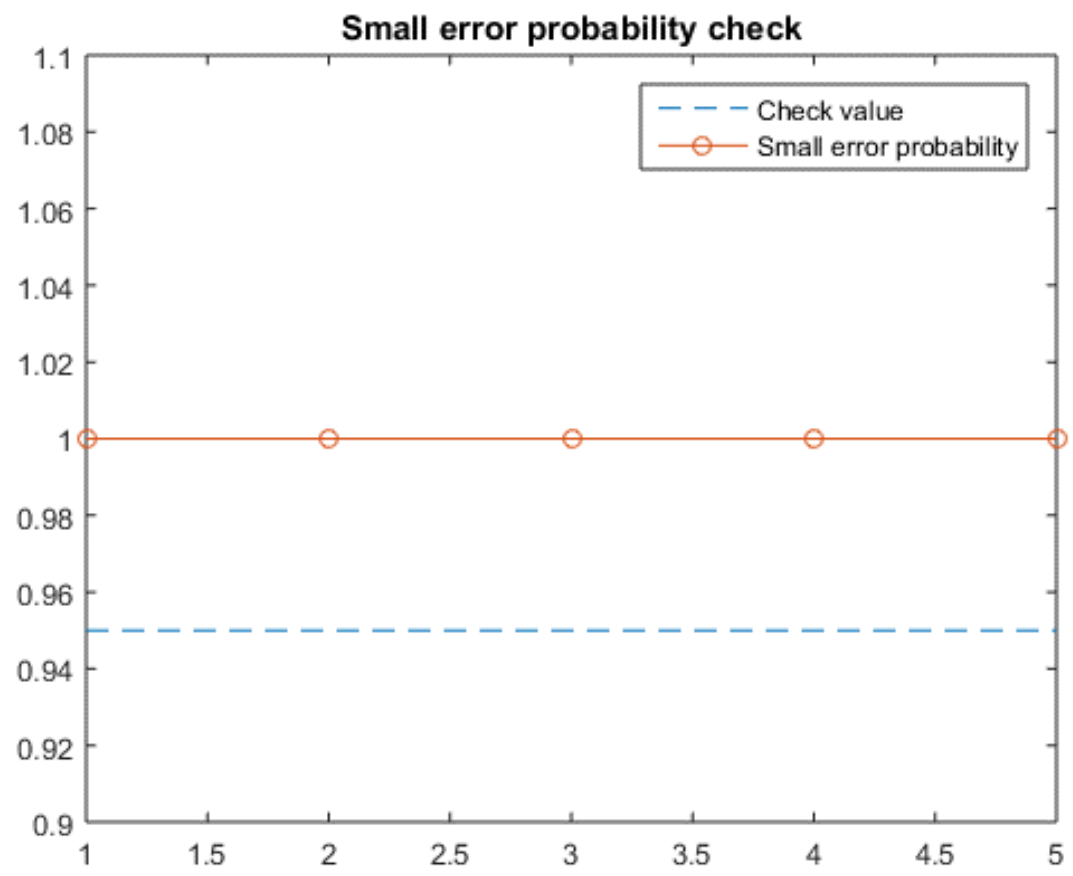

Figure 20: Small error probability check of the prediction model

The predicted values of the KPIs can assist a manager to redesign the service system. To illustrate this, the predicted bed turnover for the sixth period is 9.9469 , which is $1.5 \%$ higher than the previous period. A higher BTO rate means each bed will treat more patients. Considering the number of service days and available beds for the sixth period, managers can 
estimate the total number of patient admissions in that period; therefore, they will be able optimize the available resources. Similarly, BOR increases only by $0.55 \%$ which means inpatient occupancy rate will increase only a small amount. Increasing bed occupancy generates more revenue. Average length of stay (ALOS) decreases by $1.99 \%$ from the previous period. Length of stay will decrease when the service rate of the hospital is fast and postoperation complexity is absent. From this information, managers can assess whether their system is working properly and further quality improvement tools can be applied to give a faster service and decrease the length of stay. Hospital death rate (HDR) decreases by $4.02 \%$. Gross death rate is the overall death rate indicator of the facility. A decreasing trend in HDR can assist managers to identify activities that lead to decreased death rate and put more effort on those to further decrease the death rate. Hospital infection rate (HIR) also decreases by 4.14\%. A low HIR means the authority is monitoring infections in different healthcare units properly. Furthermore, managers can initiate different tidiness program to follow up on in order to decrease infection rate further. For some cases, like increasing ALOS of the patients, this will increase BOR which will not be a good choice as the patients may be turned away, not finding any bed, which will result in patient dissatisfaction. Managers need to find a perfect strategy to mitigate this dilemma.

Constant effort to improve treatment processes is needed to sustain performance in the market and maintain patient trust, especially in the context of Bangladesh. The findings of this research can help the management to predict the key performance indicators which will determine how well they are performing. In every organization management use different programs to improve their service or product. Healthcare managers can implement a new service improvement program and utilize this model to determine the effectiveness of their program. The results of this analysis can be very useful for the managers trying to achieve their strategic goals, and certain values of the indicators are needed comply with government rules.

\section{Conclusions, Implications of this research, Limitations and future research scope}

\subsection{Conclusions}

In modern healthcare management systems, data analytics is gaining attention from the decision-makers. The selection of input data is very important to obtain usable output. This article demonstrates an improved GM $(1,1)$ model to predict the performance of a healthcare facility. A real case is elucidated to predict the performance of a hospital. Successful implementation of both $\operatorname{GM}(1,1)$ model and linear regression model show that our proposed 
predictive model is reliable and efficient. Moreover, one of the main advantages of the grey prediction model is that is does not depend on system data or how the data are generated. When sample size is relatively small, $\operatorname{GM}(1,1)$ model is more efficient than other existing forecasting models.

\subsection{Implications of this research}

This article presents two scientific contributions to predict healthcare performance. The first is to identify the key performance indicators, namely Bed Turnover Rate (BTR), Bed Occupancy Rate (BOR), Average Length of Stay (ALOS), Hospital Death Rate (HDR), and Hospital Infection Rate (HIR). Identifying key performance indicators helps managers to analyze their investments and customer satisfaction, as well as to comply with government rules and regulations. Managers can replace these indicators according to their organization's key performance indicators. Prediction of strategic-level performance enables managers to identify healthcare's future trends and assist in giving greater priority to the indicators with problematic trends. Appropriate strategic and operational-level actions such as elimination of unnecessary activities, merge activities, implementing latest medical technologies can be adopted if any indicators do not show satisfactory performance.

For the hospital we studied, the indicators of ALOS, HDR, and HIR showed decreasing trends, whereas BTR and BOR show increasing trends over the time period. The hospital operates in a competitive environment where they need to comply with many regulations and in the meantime generate profit. Increasing BTR is good for management but it is not always accepted. Based on the combination of direct and indirect costs, turnover can be high or low. The management should address what is the perfect turnover rate for the hospital. Decreasing attributes of ALOS, HDR, and HIR in the actual model and in our prediction are preferred from the patients' point of view, while increasing BOR is profitable for the management. High BOR indicates that patients may be turned away due to insufficient availability of beds, but an increasing trend of BTR indicates that patients are released quickly. An optimum number of BTR and BOR is necessary to maintain a good service, so these measures deserve attention in healthcare management systems.

\subsection{Limitations and future research scope}

There are some shortcomings in this research. The data do not consider the actual source of data, but rather secondary sources; therefore, field level analysis may be needed to check the 
predicted values in order to gain more insight. Moreover, data keeping issues due to administrative or inputting errors may result in under-estimation of the predicted value. Increase or decrease in the data sequence is small in some cases; therefore, breakdown of the predicted value of secondary data may be necessary to determine the actual values.

Sustainability in healthcare management can be considered to achieve a rigorous prediction model. In addition, different types of optimization algorithms can be applied to improve the values of adjacent neighbour mean and thus make grey model more improved (Tamiloli et al., 2016). Different machine learning techniques like linear regression, neural network, and support vector machine can be used to predict the values of the KPIs if primary source of data is available (Abdelaziz et al., 2018). Moreover, these techniques can be incorporated with grey model to make different hybrid models like grey-ANN (Zhou et al., 2017), grey- linear regression and non-linear multivariable models (Z.-X. Wang and Ye, 2017) and so on to make robust forecasting models.

This research can be extended by considering each departmental KPIs of a healthcare unit rather than considering overall KPIs of the organization. Additionally, patients' KPIs can also be determined using related formulae to predict their future health condition using this model and thereby taking required strategic measures.

\section{References}

Abdelaziz, A., Elhoseny, M., Salama, A. S., Riad, A. M. (2018). A machine learning model for improving healthcare services on cloud computing environment. Measurement, 119, 117128.

Ahsan, M. K., Bartlema, J. (2004). Monitoring healthcare performance by analytic hierarchy process: a developing-country perspective. International Transactions in Operational Research, 11(4), 465-478.

Aletras, V., Kontodimopoulos, N., Zagouldoudis, A., Niakas, D. (2007). The short-term effect on technical and scale efficiency of establishing regional health systems and general management in Greek NHS hospitals. Health Policy, 83(2-3), 236-245.

Alolayyan, M. N. F., Mohd Ali, K. A., Idris, F., Ibrehem, A. S. (2011). Advance mathematical model to study and analyse the effects of total quality management (TQM) and operational 
flexibility on hospital performance. Total Quality Management \& Business Excellence, 22(12), 1371-1393.

Arah, O. A., Klazinga, N. S., Delnoij, D. M. J., Asbroek, A. H. A. Ten, Custers, T. (2003). Conceptual frameworks for health systems performance: a quest for effectiveness, quality, and improvement. International Journal for Quality in Health Care, 15(5), 377. article.

Arah, O. A., Westert, G. P., Hurst, J., Klazinga, N. S. (2006). A conceptual framework for the OECD Health Care Quality Indicators Project. International Journal for Quality in Health Care, 18(suppl_1), 5. article.

Austin, P. C., Steyerberg, E. W. (2015). The number of subjects per variable required in linear regression analyses. Journal of Clinical Epidemiology, 68(6), 627-636.

Badawy, M., El-Aziz, A. A. A., Idress, A. M., Hefny, H., Hossam, S. (2016). A survey on exploring key performance indicators. Future Computing and Informatics Journal, 1(12), 47-52.

Bahadori, M., Sadeghifar, J., Hamouzadeh, P., Hakimzadeh, S. M., Nejati, M. (2011). Combining multiple indicators to assess hospital performance in Iran using the Pabon Lasso Model. Australasian Medical Journal, 4(4), 175-179.

Bassioni, H. A., S.M.ASCE;, Price;, A. D. F., Hassan, T. M., M.ASCE. (2004). Performance Measurement in Construction. Journal of Management in Engineering, 20(2), 42-50.

Belciug, S., Gorunescu, F. (2015). Improving hospital bed occupancy and resource utilization through queuing modeling and evolutionary computation. Journal of Biomedical Informatics, 53, 261-269.

Bhatia, M., Sood, S. K. (2017). A comprehensive health assessment framework to facilitate IoT-assisted smart workouts: A predictive healthcare perspective. Computers in Industry, 92-93, 50-66. JOUR.

Bilodeau, D., Cr?mieux, P.-Y., Ouellette, P. (2009). Hospital performance in a noncompetitive environment. Applied Economics, 41(4), 459-468.

Bilow, R. M., Shanmuganathan, K., Harris, J. H. (2016). Toward Reduction of Post?Hospital Admission Death Rate Caused by Acute Traumatic Aortic Tear. The Journal of Emergency Medicine, 51(2), 114-119. 
Bradea, I., Mărăcine, V. (2015). Grey incidence between KPIs and hospital performance. Grey Systems: Theory and Application, 5(2), 234-243.

Civan, F. (2007). MODEL-ASSISTED ANALYSIS AND INTERPRETATION OF LABORATORY AND FIELD TESTS. In Reservoir Formation Damage (pp. 670-738). Elsevier.

Cucciare, M. A., O’Donohue, W. (2006). Predicting future healthcare costs: how well does risk-adjustment work? Journal of Health Organization and Management, 20(2), 150-162.

Cunningham, J. B., Kernohan, W. G., Sowney, R. (2005). Bed occupancy and turnover interval as determinant factors in MRSA infections in acute settings in Northern Ireland: 1 April 2001 to 31 March 2003. Journal of Hospital Infection.

Deng, J. L. (1989). Introduction to Grey System Theory. J. Grey Syst., 1(1), 1-24. article.

Dey, P. K., Hariharan, S., Despic, O. (2008). Managing healthcare performance in analytical framework. Benchmarking: An International Journal, 15(4), 444-468.

Ding, R., McCarthy, M. L., Desmond, J. S., Lee, J. S., Aronsky, D., Zeger, S. L. (2010). Characterizing waiting room time, treatment time, and boarding time in the emergency department using quantile regression. Academic emergency medicine : official journal of the Society for Academic Emergency Medicine, 17(8), 813-823. Journal Article, Multicenter Study, Research Support, U.S. Gov't, P.H.S.

Elg, M., Palmberg Broryd, K., Kollberg, B. (2013). Performance measurement to drive improvements in healthcare practice. International Journal of Operations \& Production Management, 33(11/12), 1623-1651.

Elsamadicy, A. A., Wang, T. Y., Back, A. G., Sergesketter, A., Warwick, H., Karikari, I. O., Gottfried, O. N. (2016). Impact of Intraoperative Steroids on Postoperative Infection Rates and Length of Hospital Stay: A Study of 1200 Spine Surgery Patients. World Neurosurgery, 96, 429-433.

Funtowicz, S. O., Ravetz, J. R. (1990). Uncertainty and Quality in Science for Policy. Dordrecht: Springer Netherlands.

Furham, A. (2004). Performance management systems. European Business Journal, 16(2), 8394. 
Goshtasebi, A., Vahdaninia, M., Gorgipour, R., Samanpour, R., Maftoon, F., Farzadi, F., Ahmadi, F. (2009). Assessing Hospital Performance by the Pabon Lasso Model. Iranian Journal of public health, 38(2), 119-124.

Green, S. B. (1991). How Many Subjects Does It Take To Do A Regression Analysis. Multivariate Behavioral Research, 26(3), 499-510.

Grøndahl, A. V., Hall-Lord, M. L., Karlsson, I., Appelgren, J., Wilde-Larsson, B. (2013). Exploring patient satisfaction predictors in relation to a theoretical model. International Journal of Health Care Quality Assurance, 26(1), 37-54.

$\mathrm{Gu}$, X., Itoh, K. (2016). Performance indicators: healthcare professionals? views. International Journal of Health Care Quality Assurance, 29(7), 801-815.

Guidolin, M., Pedio, M. (2018). Linear Regression Model. In Essentials of Time Series for Financial Applications (pp. 1-39). Elsevier.

Hsu, C., Wen, Y. (1998). Improved grey prediction models for the trans?pacific air passenger market. Transportation Planning and Technology, 22(2), 87-107.

Hua, H. (2009). Modeling and simulation for an improved grey theory approach in cars. 2009 International Conference on E-Business and Information System Security, EBISS 2009.

Hyndman, R. J., Koehler, A. B. (2006). Another look at measures of forecast accuracy. International Journal of Forecasting, 22(4), 679-688.

Imamgholi, S., Firouzabadi, S. M. A. K., Goharinezhad, S., Dehcheshmeh, N. F., Heidarinejad, A., Azmal, M., A. (2014). Assessing the efficiency of hospitals by using Pabon Lasso graphic model. Journal of Research \& Health, 4(4), 890-897.

Jones, H. E., Spiegelhalter, D. J. (2012). Improved probabilistic prediction of healthcare performance indicators using bidirectional smoothing models. Journal of the Royal Statistical Society: Series A (Statistics in Society), 175(3), 729-747.

Kang, J., Zhao, H. (2012). Application of Improved Grey Model in Long-term Load Forecasting of Power Engineering. Systems Engineering Procedia, 3, 85-91.

Khalifa, M., Zabani, I. (2016). Utilizing health analytics in improving the performance of healthcare services: A case study on a tertiary care hospital. Journal of Infection and 
Public Health, 9(6), 757-765.

Lee, Y.-C., Wu, C.-H., Tsai, S.-B. (2014). Grey system theory and fuzzy time series forecasting for the growth of green electronic materials. International Journal of Production Research, 52(10), 2931-2945.

Leggat, S. G., Narine, L., Lemieux-Charles, L., Barnsley, J., Baker, G. R., Sicotte, C., ... Bilodeau, H. (1998). A review of organizational performance assessment in health care. Health services management research, 11(1), 3-23. Journal Article, Review.

Li, C. (2011). The Improved Background Value of Ameliorating GM $(1,1)$ Model and Its Application. 2nd International Conference on Intelligent Control and Information Processing, 131-134.

Li, Z., Jiang, Y., Yue, J., Zhang, L., Li, D. (2012). An Improved Gray Model For Aquaculture Water Quality Prediction. Intelligent Automation \& Soft Computing, 18(5), 557-567.

Liang, J. (2013). Corroborative analysis tools. In Chemical Modeling for Air Resources (pp. 241-265). Elsevier.

Liao, M.-S., Liang, G.-S., Chen, C.-Y. (2013). Fuzzy grey relation method for multiple criteria decision-making problems. Quality \& Quantity, 47(6), 3065-3077.

Liu, S., Forrest, J., Yang, Y. (2012). A brief introduction to grey systems theory. Grey Systems: Theory and Application, 2(2), 89-104.

Liu, S., Lin, Y. (2011). Grey Systems (Vol. 68). Berlin, Heidelberg: Springer Berlin Heidelberg.

Love, D., Revere, L., Black, K. (2008). A current look at the key performance measures considered critical by health care leaders. Journal of health care finance, 34(3), 19-33.

Madhi, M., Mohamed, N. (2017). An Initial Condition Optimization Approach for Improving the Prediction Precision of a $\operatorname{GM}(1,1)$ Model. Mathematical and Computational Applications, 22(1), 21.

Magee, H., Davis, L.-J., Coulter, A. (2003). Public views on healthcare performance indicators and patient choice. Journal of the Royal Society of Medicine.

Mao, M., Chirwa, E. C. (2006). Application of grey model $\operatorname{GM}(1,1)$ to vehicle fatality risk estimation. Technological Forecasting and Social Change, 73(5), 588-605. 
Meier, H., Lagemann, H., Morlock, F., Rathmann, C. (2013). Key Performance Indicators for Assessing the Planning and Delivery of Industrial Services. Procedia CIRP, 11, 99-104.

Milstein, J. A., Everson, J., Lee, S. Y. D. (2015). EHR Adoption and Hospital Performance: Time-Related Effects. Health Services Research, 50(6).

Moullin, M. (2007). Performance measurement definitions: linking performance measurement and organisational excellence. International journal of health care quality assurance.

Neely, A.D., Adams, C. and Kennerley, M. (2002). The Performance Prism: The Scorecard for Measuring and Managing Stakeholder Relationships. London: Financial Times/Prentice Hall.

Nolte, E., McKee, M. (2003). Measuring the health of nations: analysis of mortality amenable to health care. $B M J, 327(7424), 1129$. article.

OECD. (2015). Health at a Glance 2015. OECD Publishing.

Osborn, C. E. (2008). Essentials of Statistics in Health Information Technology. The Ohio State University Health System, Ohio: Jones and Barlett Learning.

Protty, M. B., Lacey, A., Smith, D., Hannoodee, S., Freeman, P. (2017). Increased morbidity, mortality and length of in-hospital stay for patients with acute coronary syndrome with pre-morbid psychiatric diagnoses. International Journal of Cardiology, 236, 5-8.

Rajesh, R. (2016). Forecasting supply chain resilience performance using grey prediction. Electronic Commerce Research and Applications, 20, 42-58.

Samvedi, A., Jain, V. (2013). A grey approach for forecasting in a supply chain during intermittentdisruptions. Engineering Applications of Artificial Intelligence, 26(3), 10441051.

Schmidt, A. F., Finan, C. (2018). Linear regression and the normality assumption. Journal of Clinical Epidemiology, 2-7.

Sorup, M. C., Jacobsen, P. (2013). Healthcare performance turned into decision support. Journal of Health Organization and Management, 27(1), 64-84.

Sullivan, E., Shelley, J., Rainey, E., Bennett, M., Prajapati, P., Powers, M. B., ... Warren, A. M. (2017). The association between posttraumatic stress symptoms, depression, and 
length of hospital stay following traumatic injury. General Hospital Psychiatry, 46, 4954.

Sun, Y., Heng, B. H., Tay, S. Y., Tan, K. B. (2015). Unplanned 3-day re-attendance rate at Emergency Department (ED) and hospital?s bed occupancy rate (BOR). International Journal of Emergency Medicine, 8(1), 32.

Supeekit, T., Somboonwiwat, T., Kritchanchai, D. (2016). DEMATEL-modified ANP to evaluate internal hospital supply chain performance. Computers \& Industrial Engineering, 102, 318-330. article.

Tamiloli, N., Venkatesan, J., Vijaya Ramnath, B. (2016). A grey-fuzzy modeling for evaluating surface roughness and material removal rate of coated end milling insert. Measurement, $84,68-82$.

Tan, G.-J. (2000). The structure method and application of background value in grey system GM (1, 1) model (I). Systems Engineering-Theory \& Practice, 20(4), 98-103. article.

Tsai, C. F., Lu, S. L. (2015). Novel grey models for the trend forecast of Taiwan waste gas apparatus. International Journal of Environmental Technology and Management, 18(2), 170.

Unnikrishna Pillai, J., Sanghrajka, I., Shunmugavel, M., Muthuramalingam, T., Goldberg, M., Littlefair, G. (2018). Optimisation of multiple response characteristics on end milling of aluminium alloy using Taguchi-Grey relational approach. Measurement, 124, 291-298.

van Asselt, M. B. A., Rotmans, J. (2002). Uncertainty in Integrated Assessment Modelling. Climatic Change, 54(1/2), 75-105.

van der Geer, E., van Tuijl, H. F. J. M., Rutte, C. G. (2009). Performance management in healthcare: Performance indicator development, task uncertainty, and types of performance indicators. Social Science and Medicine.

Veillard, J., Champagne, F., Klazinga, N., Kazandjian, V., Arah, O. A., Guisset, A.-L. (2005). A performance assessment framework for hospitals: the WHO regional office for Europe PATH project. International Journal for Quality in Health Care, 17(6), 487. article.

Walburg, J., Bevan, H., Wilderspin, J., Lemmens, K. (2005). Performance Management in Healthcare. Performance Management in Healthcare: Improving Patient Outcomes: An 
Integrated Approach. Routledge.

Wang, Q., Liu, L., Wang, S., Wang, J.-Z., Liu, M. (2017). Predicting Beijing's tertiary industry with an improved grey model. Applied Soft Computing, 57, 482-494.

Wang, Q., Wang, Z., Mourelatos, Z. P., Fu, J. (2014). Estimation of measurement results with poor information using the dynamic bootstrap grey method. Measurement, 57, 138-147.

Wang, Y., Dang, Y., Liu, S. (2010). Reliability Growth Prediction Based on an Improved Grey Prediction Model. International Journal of Computational Intelligence Systems, 3(3), $266-273$.

Wang, Z.-X., Ye, D.-J. (2017). Forecasting Chinese carbon emissions from fossil energy consumption using non-linear grey multivariable models. Journal of Cleaner Production, $142,600-612$.

Weir, E., D’Entremont, N., Stalker, S., Kurji, K., Robinson, V. (2009). Applying the balanced scorecard to local public health performance measurement: deliberations and decisions. BMC Public Health, 9(1), 127.

Xia, T., Jin, X., Xi, L., Zhang, Y., Ni, J. (2015). Operating load based real-time rolling grey forecasting for machine health prognosis in dynamic maintenance schedule. Journal of Intelligent Manufacturing, 26(2), 269-280.

Xiaofei, L., Renfang, H. (2014). Grey Forecasting Model Based on Interpolation Optimization in Malignant Tumor. SHS Web of Conferences, 6, 3003.

Zaman, K., Mahadevan, S. (2013). Robustness-Based Design Optimization of Multidisciplinary System Under Epistemic Uncertainty. AIAA Journal, 51(5), 1021-1031.

Zhou, J., Ren, J., Yao, C. (2017). Multi-objective optimization of multi-axis ball-end milling Inconel 718 via grey relational analysis coupled with RBF neural network and PSO algorithm. Measurement, 102, 271-285.

\section{Appendix}

Table A1: Mean relative error and filtering error checking with different values of the parameters

$(\varphi, \omega) \quad$ Mean Relative Error $(\%) \quad(\varphi, \omega) \quad$ Mean Relative Error (\%) 


\begin{tabular}{|c|c|c|c|c|}
\hline \multirow{5}{*}{$(0.5,0.1)$} & $1.27182 \%$ & \multirow{4}{*}{$(0.6,0.1)$} & \multirow{3}{*}{$\begin{array}{l}0.56258 \% \\
0.19371 \% \\
0.69486 \%\end{array}$} & \multirow{6}{*}{$\begin{array}{l}\text { Highlights: } \\
\qquad \text { A grey } \\
\text { approach to } \\
\text { predicting key }\end{array}$} \\
\hline & $0.44197 \%$ & & & \\
\hline & $1.63003 \%$ & & & \\
\hline & $3.33120 \%$ & & $1.38798 \%$ & \\
\hline & $4.07223 \%$ & & $1.67475 \%$ & \\
\hline \multirow{5}{*}{$(0.5,0.2)$} & $1.02977 \%$ & \multirow{5}{*}{$(0.6,0.2)$} & $0.38172 \%$ & \\
\hline & $0.35795 \%$ & & $0.13058 \%$ & \multirow{10}{*}{$\begin{array}{l}\text { healthcare } \\
\text { performance } \\
\text { indicators is } \\
\text { used. } \\
\text { - Key } \\
\text { performance }\end{array}$} \\
\hline & $1.32059 \%$ & & $0.45886 \%$ & \\
\hline & $2.69997 \%$ & & $0.90027 \%$ & \\
\hline & $3.29996 \%$ & & $1.07453 \%$ & \\
\hline \multirow{5}{*}{$(0.5,0.3)$} & $0.80528 \%$ & \multirow{5}{*}{$(0.6,0.3)$} & $0.21195 \%$ & \\
\hline & $0.27984 \%$ & & $0.07120 \%$ & \\
\hline & $1.03114 \%$ & & $0.23585 \%$ & \\
\hline & $2.10646 \%$ & & $0.43757 \%$ & \\
\hline & $2.57220 \%$ & & $0.85168 \%$ & \\
\hline \multirow{5}{*}{$(0.5,0.4)$} & $0.59651 \%$ & \multirow{5}{*}{$(0.6,0.4)$} & $0.12977 \%$ & \\
\hline & $0.20703 \%$ & & $0.04889 \%$ & \multirow{29}{*}{$\begin{array}{l}\text { indicators for } \\
\text { healthcare } \\
\text { units are } \\
\text { proposed. }\end{array}$} \\
\hline & $0.75979 \%$ & & $0.20971 \%$ & \\
\hline & $1.54739 \%$ & & $0.51466 \%$ & \\
\hline & $1.88522 \%$ & & $0.66630 \%$ & \\
\hline \multirow{5}{*}{$(0.5,0.5)$} & $0.59651 \%$ & \multirow{5}{*}{$(0.6,0.5)$} & $0.18534 \%$ & \\
\hline & $0.20703 \%$ & & $0.07910 \%$ & \\
\hline & $0.75979 \%$ & & $0.34095 \%$ & \\
\hline & $1.54739 \%$ & & $0.60675 \%$ & \\
\hline & $1.88522 \%$ & & $0.69783 \%$ & \\
\hline \multirow{5}{*}{$(0.5,0.6)$} & $0.21996 \%$ & \multirow{5}{*}{$(0.6,0.6)$} & $0.27881 \%$ & \\
\hline & $0.07532 \%$ & & $0.11192 \%$ & \\
\hline & $0.26501 \%$ & & $0.46560 \%$ & \\
\hline & $0.52128 \%$ & & $0.86771 \%$ & \\
\hline & $0.67386 \%$ & & $1.04911 \%$ & \\
\hline \multirow{5}{*}{$(0.5,0.7)$} & $0.05919 \%$ & \multirow{5}{*}{$(0.6,0.7)$} & $0.37445 \%$ & \\
\hline & $0.03184 \%$ & & $0.14299 \%$ & \\
\hline & $0.12355 \%$ & & $0.58414 \%$ & \\
\hline & $0.28060 \%$ & & $1.19803 \%$ & \\
\hline & $0.47942 \%$ & & $1.52008 \%$ & \\
\hline \multirow{5}{*}{$(0.5,0.8)$} & $0.13988 \%$ & \multirow{5}{*}{$(0.6,0.8)$} & $0.50157 \%$ & \\
\hline & $0.06209 \%$ & & $0.17951 \%$ & \\
\hline & $0.26578 \%$ & & $0.71733 \%$ & \\
\hline & $0.42926 \%$ & & $1.56045 \%$ & \\
\hline & $0.53326 \%$ & & $1.97025 \%$ & \\
\hline \multirow{5}{*}{$(0.5,0.9)$} & $0.26073 \%$ & \multirow{5}{*}{$(0.6,0.9)$} & $0.62210 \%$ & \\
\hline & $0.09745 \%$ & & $0.22205 \%$ & \\
\hline & $0.40040 \%$ & & $0.88095 \%$ & \\
\hline & $0.82277 \%$ & & $1.90676 \%$ & \\
\hline & $1.04281 \%$ & & $2.40095 \%$ & \\
\hline
\end{tabular}

- Sensitivity analysis is performed to check the robustness of the approach.

- Managerial implications are suggested. 